\title{
Healing the world: a geosynthetics solution
}

\author{
N. Touze ${ }^{1}$ \\ ${ }^{1}$ Deputy Director, Université Paris-Saclay, INRAE, SDAR, 78352, Jouy-en-Josas, France, \\ E-mail: nathalie.touze@inrae.fr
}

Received 16 November 2018, revised 20 February 2020, accepted 28 April 2020, published 05 October 2020

\begin{abstract}
There seems to be no consensus about whether the world is currently going through an unpreceded crisis. The conditions of life have greatly improved since the 17 th century in terms of food quality and quantity, water quality, life expectancy, poverty, violence, environment, freedom, social equality, education, and so on. Some could argue that the good old days were terrible! However, a number of unacceptable conditions remain in our world and new ones have emerged, all requiring urgent improvements. The world is a complex organism, experiencing numerous troubles: economic and financial crises, environmental crises, agricultural crises, sanitary crises, psychological and identity-related crises, crises of values and sense, political crises, and so on. When faced with such a systemic crisis, the solution must be global. How can geosynthetics and the geosynthetics community contribute to resolving these crises and help to heal the world? The objective of this Giroud lecture is to analyse recent developments in geosynthetics in search of evidence of our contribution today to ensuring water quality for all, feeding the world, protecting the environment, mitigating natural disasters, facilitating economic solutions, and connecting people to help them to learn to live together according to universal human values.
\end{abstract}

KEYWORDS: Geosynthetics, global, values, water, agriculture, environment, sustainability

REFERENCE: Touze, N. (2021). Healing the world: a geosynthetics solution. Geosynthetics International, 28, No. 1, 1-31. [https://doi.org/10.1680/jgein.20.00023]

\section{INTRODUCTION}

The United Nations program 'Transforming our world: The 2030 Agenda for Sustainable Development' establishes 17 sustainable development goals (SDGs) to guide decisions taken by nations and organisations over the next 15 years (UN 2015). The SDGs address the global challenges we face, including those related to poverty, inequality, climate change, environmental degradation, peace and justice. The 17 SDGs are all interconnected.

The world we live in indeed is a complex organism with numerous troubles: economic and financial crises, environmental crises, agricultural crises, sanitary crises, psychological and identity-related crises, crises of values and sense, political crises, and so on. When faced with such a systemic crisis, the solution must be global (Lenoir 2012).

Dixon et al. (2017) were the first authors in the International Geosynthetics Society (IGS) to mention this UN document and the role geosynthetics could play in achieving SDG 6, clean water and sanitation; SDG 9, industry, innovation, and infrastructure; SDG 12, responsible consumption and production; SDG 13, climate action; and SDG 17, partnerships for the goals.

The aim of the present paper is to evince how geosynthetics and the IGS can contribute to resolving, to some extent, some of the many facets of the global crisis by supplying quality water to all, feeding the world, protecting the environment, mitigating natural disasters, providing economic solutions and connecting people, including by helping them live together.

Unlike most geosynthetics papers or lectures, which are thematic, this paper does not focus on a given aspect of geosynthetics but instead provides a systemic view of what geosynthetics can offer society as a whole. Given this objective, diverse fields are discussed, without aiming to discuss all possible fields or to delve deeply into details, but rather to illustrate where and how geosynthetics offer solutions to mitigate the global crisis. The intention is not to be overly technical but rather to show explicitly the added value of geosynthetics and where they prove to be necessary.

Another aim of this paper is to show that the IGS, which is composed of human beings, is founded not only on its robust technical capabilities, but also on the strength of its values.

Section 2 starts the discussion with a brief overview of some of the issues our society faces today, with an emphasis on the connections between the various aspects of the current crisis. Particular attention is given to climate change and how it aggravates some other aspects of the crisis. 
Section 3 briefly overviews geosynthetics, describing what they are and presenting the primary families of materials and their functions.

Section 4 addresses the issue of quality water for all: it presents the main structures that contribute to capturing, transporting, storing, and distributing freshwater and discusses the functions that geosynthetics provide for the requisite infrastructure.

Section 5 discusses how geosynthetics can contribute to feeding the world. The question of erosion control is treated first, following which crop protection and enhancement and fish farming are discussed. Techniques to manage agricultural waste are also presented, ultimately leading to insights on how geosynthetics can contribute to sustainable agricultural practices.

Section 6 addresses environmental protection, starting with the use of geosynthetics to control pollution from landfills and mining sites, highlighting in particular how geosynthetics can contribute to treating sludge and sediments. The production of renewable energy from waste or at waste-treatment sites is also discussed, and elements are presented to show how geosynthetics can help mitigate climate change.

Section 7 focuses on the mitigation of natural disasters, with the exception that geosynthetics for earthquake mitigation is not discussed. Focus is placed instead on situations where climate change leads to water problems that threaten life and infrastructure. Insights are given into the use of geosynthetics to prevent coastal erosion, protect against flooding and prevent landslides.

Section 8 discusses the economic solutions provided by geosynthetics and presents various applications in which geosynthetics provide financial benefits.

Finally, Section 9 notes first that living together requires that people be connected. Geosynthetics contribute to this by improving road and railway networks. The second part of Section 9 is dedicated to human values, how they are implemented in the IGS, and how they foster technical, environmental and economic developments to build a new, sustainable, global society.

\section{THE WORLD WE LIVE IN}

\subsection{Quality water for all}

Access to water, sanitation, and hygiene is a human right (UN 2015). However, water scarcity currently affects over $40 \%$ of the global population and is projected to rise (UN 2015). Pollution, global warming and population growth all combine to produce severe negative impacts going forward.

The World Health Organization estimates that about half of the population of low- or middle-income countries suffers from disease caused by water issues, be it a lack of potable water or inadequate wastewater treatment. Waterand sanitation-related diseases remain among the major causes of death worldwide of children under five (UN 2015). All told, 2.6 million people die each year due to the consumption of unsanitary water.
Water also is a geopolitical issue: 14 countries have to share their water resources with other countries. Tensions already exist related to resources and borders, which are of minimal concern to rivers (Blanchet 2017). Water management and conservation will be a major challenge in the 21st century, especially in Africa (Giroud and Plusquellec 2017). Figure 1 summarises the various interactions mentioned above as well as others to be discussed in the following subsections.

\subsection{Feeding the world}

Agriculture, in its various guises, occupies $40 \%$ to $50 \%$ of the planet's land surface. Although the cultivated area increased only by $12 \%$ from 1961 to 2009 , agricultural production increased by about $300 \%$ over the same period. This growth is connected not only to the increased use of fertilisers but also to new plant varieties, some of which are controversial because of their effect on biodiversity.

Agriculture also accounts for $10 \%$ to $12 \%$ of the total anthropogenic greenhouse gas emissions, 50\% of global methane emissions, and $60 \%$ of global nitrous oxide emissions and grew annually at $0.9 \%$ from 1990 to 2010 . Virtually all emissions attributed to agriculture are the result of food production to feed an ever-growing world population, which is expected to increase by over $50 \%$ to 10.8 billion by 2100 (Porter and Reay 2015).

In addition to land use and greenhouse gases, agriculture accounts for $70 \%$ of global water consumption (Lenoir 2012). Intensive agriculture has degraded aquifers both by directly polluting them and by overexploitation through irrigation (Norberg 2016). Furthermore, the dependence on water tends to increase with increasing food demand. A consequence of these forces is that, since the beginning of the 20th century, $50 \%$ of the world's wetlands have disappeared (Lenoir 2012).

Thus, although the expansion of agriculture and the use of fertilisers and pesticides have contributed to reducing hunger, they have also transformed many areas into dead zones (Norberg 2016).

\subsection{Environmental crisis}

\subsubsection{Pollution}

The Lancet Commission on Pollution and Health (The Lancet Commission 2017) defines pollution as unwanted material, often dangerous, that is introduced into Earth's environment as the result of human activity, and which threatens human health and harms ecosystems. According to this commission, anthropogenic pollution is today the largest environmental cause of disease and premature death in the world. Pollution disproportionately kills the poor and the vulnerable. Pollution is also costly because it decreases productivity and increases welfare losses, which are estimated at $6.2 \%$ of global economic output.

Pollution also endangers planetary health, destroys ecosystems, and is intimately linked to global climate change. Burning is a major source of greenhouse gases and a major source of pollution. 


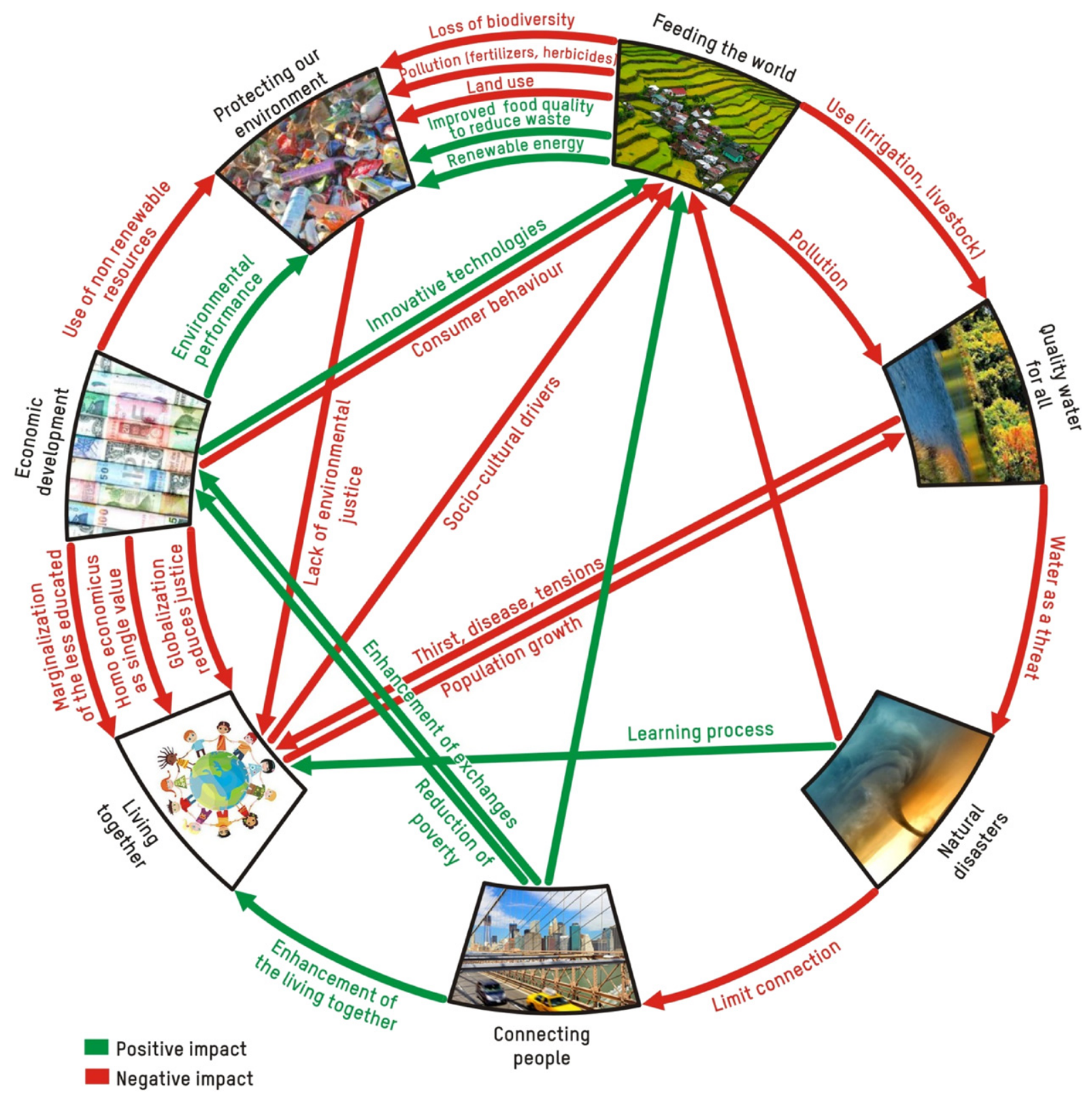

Figure 1. Some connections between the axes for action of geosynthetics and the IGS for this Giroud lecture

In many parts of the world, pollution is increasing. Although household air and water pollution, which is associated with profound poverty and traditional lifestyles, is slowly declining, ambient-air pollution, chemical pollution and soil pollution, which are caused by industry, mining, electric-power generation, mechanised agriculture and petroleum-powered vehicles, are all on the rise, with the most marked increases occurring in the rapidly developing low- and middle-income countries.

Pollution control is a step toward reaching many of the SDGs: in addition to improving health in countries around the world (SDG 3), pollution control should help alleviate poverty (SDG 1), improve access to clean water and improve sanitation (SDG 6), promote social justice (SDG 10), build sustainable cities and communities (SDG 11) and protect land and water (SDGs 14 and 15). Pollution control should also benefit from efforts to slow the pace of climate change (SDG 13) (The Lancet
Commission on Pollution and Health (The Lancet Commission 2017)).

\subsubsection{Climate change and its consequences}

Although improved production and transportation have contributed to reducing poverty, their dependence on fossil fuels means that they have also released significant amounts of greenhouse gases into the atmosphere.

The warming of Earth's climate is unequivocal, as is the fact that the dominant cause of global warming since the mid-20th century is human activity. What are the consequences of climate change? Forzieri et al. (2017) state that climate change is one of the biggest global threats to human health in the 21 st century. They report that weather-related disasters, and heatwaves in particular, could affect about two-thirds of the European population annually by the year 2100 compared with $5 \%$ affected during the period 1981-2010. Premature mortality due to 
extreme weather could become the greatest environmental risk factor.

In general, the variability of extreme events will increase (IPPC 2014; Dixon et al. 2017). For example, an increase in temperatures will undoubtedly increase the frequency and intensity of cyclones. However, the most important factor in inundations will be the rise in sea level. An increase by a few millimetres will render useless existing defences along the coast and may increase by over an order of magnitude the costs related to inundations (Vanleberghe 2017).

The primary greenhouse gas is $\mathrm{CO}_{2}$, the rising levels of which significantly affect global food production, in addition to its direct effect on crop-nutrient content. In fact, climate change is expected to disrupt global food production through a variety of mechanisms (Myers 2017).

It stands to reason that increasingly severe weather events and reduced crop yields in the tropics, coupled with growing water scarcity and land degradation, will drive an increasing number of people, often of scarce means, to seek new homes. Forced displacement will have a massive impact on human health, to the point that displacement and conflict may contribute the most to disease associated with global environmental change (Myers 2017). Stabilising tens of millions of people on their own territory and allowing them to produce their own food and develop local economies are vital for ensuring peace (L'Humanité 2017).

Climate change is the consequence of increasing population and increasing consumerism. Figure 2 shows the areas directly affected by climate change: feeding the world, threatening human health, disrupting food production, migrations and wars, and an increasing frequency and magnitude of natural disasters.

\subsection{Economic disparities and poverty}

Despite the recent focus on reducing poverty, over 700 million human beings still live in extreme poverty (Norberg 2016). The first SDG is to end poverty in all its forms, which is the greatest global challenge and an indispensable requirement for sustainable development (UN 2015).

Economic development and the concomitant decrease in poverty correlate with decreased rates of infant mortality, which translates into decreased birth rates and eventually modifies the rate of population growth (Norberg 2016).

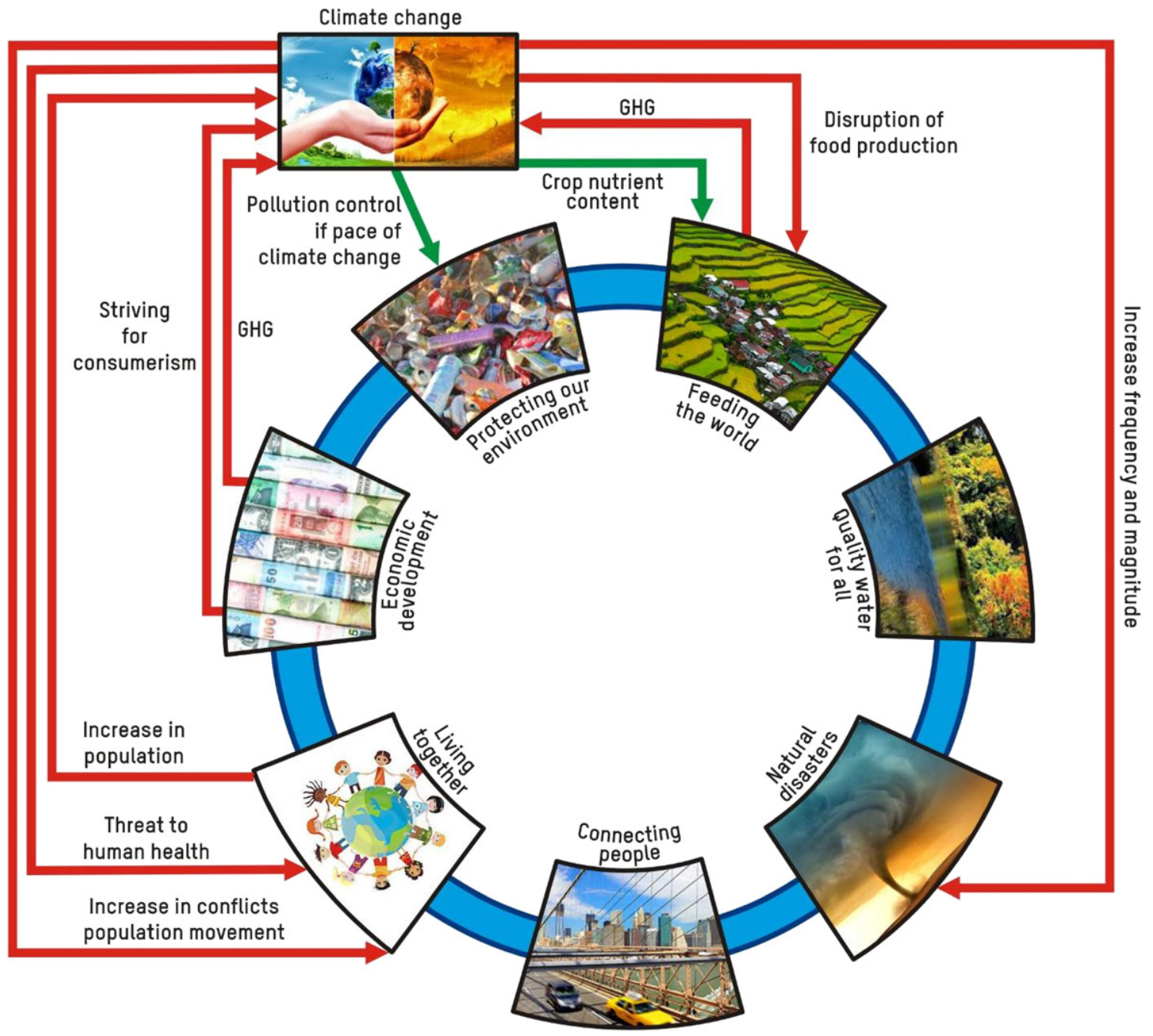

Figure 2. Impacts on and of climate change on feeding the world, environment, natural disasters, economic development and living together 
Another good reason to continue fighting poverty is that wealth appears to be a major factor promoting environmental consciousness and no longer seems to be an obstacle to ecological durability: when people are confident that their children will live in good conditions, be educated to prepare their future, and live longer, they become more concerned by the quality of their environment (Norberg 2016). Energy, money, and time can also be spent on these fronts, once such livelihoods are guaranteed.

Greater wealth mitigates the damage of natural disasters through better education, prevention, construction, monitoring and alert systems (Norberg 2016).

\subsection{Natural disasters}

According to the United Nations, $95 \%$ of all deaths due to natural disasters between 1970 and 2008 occurred in low- or middle-income countries. Although human intervention cannot prevent natural disasters, better early-warning systems, better education about evacuation strategies, and faster and more effective emergency responses would surely mitigate the consequences (Parker 2013). As stated by Brandl (2010), even the most costly protective measures cannot eliminate the residual risk. The ideal of 'absolute safety', often demanded by the public, politicians, media or lawyers, cannot be achieved in reality.

However, that natural disasters are unavoidable does not mean that nothing should be done to mitigate their consequences (Brandl 2010, 2011; Yoo 2015). Section 7 explains how geosynthetics can contribute to mitigating natural disasters.

\subsection{Connecting people}

The science of planetary health places us in new ethical terrain. It teaches us that each person alive today or coming in a future generation is connected to everyone else. Every decision we make about what we eat, how we move around, what we buy or even whether we have a child affects our planet's natural system and, as a result, the health and wellbeing of every other person on the planet. Although the impact of each individual decision is infinitesimally small, the collective impact is enormous (Myers 2017). We are all connected.

However, territorial discontinuities exist in the same way that environmental justice is not uniform around the world. Territorial discontinuities create an increasing gap between large cities, symbols of successful globalisation, and their surroundings, where the economic flows are stymied. Investment in transport infrastructure is crucial to provide isolated people with the possibility of social mobility (Levita 2017). Section 9.1 describes how geosynthetics are used in the construction of transport infrastructure and contribute to connecting people, thereby supporting SDG 11.

\subsection{Living together}

During the Enlightenment, much of Western civilisation embraced a Cartesian dualism, which emphasises the realm of the material and scientifically accessible over the spiritual. Although the explosion of scientific understanding and technological mastery that followed engendered enormous benefits for humanity, it might also have blinded us to other forms of knowledge (Myers 2017). Today, for the first time in human history, we face the emergence of a single, tightly coupled human socio-ecological system of planetary scope. We are more interconnected and interdependent than ever before, which increases enormously our individual and collective responsibility.

Unfortunately, this broad civilisation is not the fruit of an equitable dialog between cultures: it is heavily tilted by the technological turmoil that produced it (Lenoir 2012). According to Lenoir, this civilisation is the result of the hegemony of the West, its technical control, and some of its values, good or bad. Although humanity has long expressed a deep desire for emancipation of the individual, consumerism as the unique path toward self-realisation is leading an increasing number of us to an impasse (Lenoir 2012). Healing the world requires a reformulation of the universal ethical values through an equitable dialogue between cultures and an overhaul of the relationship between humans and nature and between man and woman; a relationship that does not involve domination (Lenoir 2012). Section 9.2 discusses the universal values that could form the foundation of such a civilisation and how we might bring them to life in the IGS.

\subsection{Our interdependent world}

The previous sections present evidence supporting the view that the various aspects of our world cannot be considered separately because they are in constant interaction. The world must be considered as it is: a complex organism that currently suffers from various ills (Lenoir 2012). The resolution of the worldwide crisis or, in more positive language, the continuous progress in the various areas described above (i.e. supplying quality water to all, feeding everyone, protecting the environment, mitigating natural disasters, supporting economic development, connecting people, living together) can only occur if it involves and connects all of these areas. As stated by the United Nations, sustainable development is a goal that must be achieved in a balanced and integrated manner. Figure 3 shows how the 17 SDGs from the United Nations' program are distributed around these various areas.

After briefly presenting in Section 3 the field of geosynthetics, the remainder of this paper evaluates how geosynthetics contribute to developing strategies to adapt and overcome the challenges facing the world.

\section{GEOSYNTHETICS AND THEIR FUNCTIONS}

A geosynthetic is defined by the international standard EN ISO 10318 (AFNOR, n.d.) as a product, at least one of whose components is made from a synthetic or natural polymer, in the form of a sheet, a strip, or a threedimensional structure, used in contact with soil and/or 


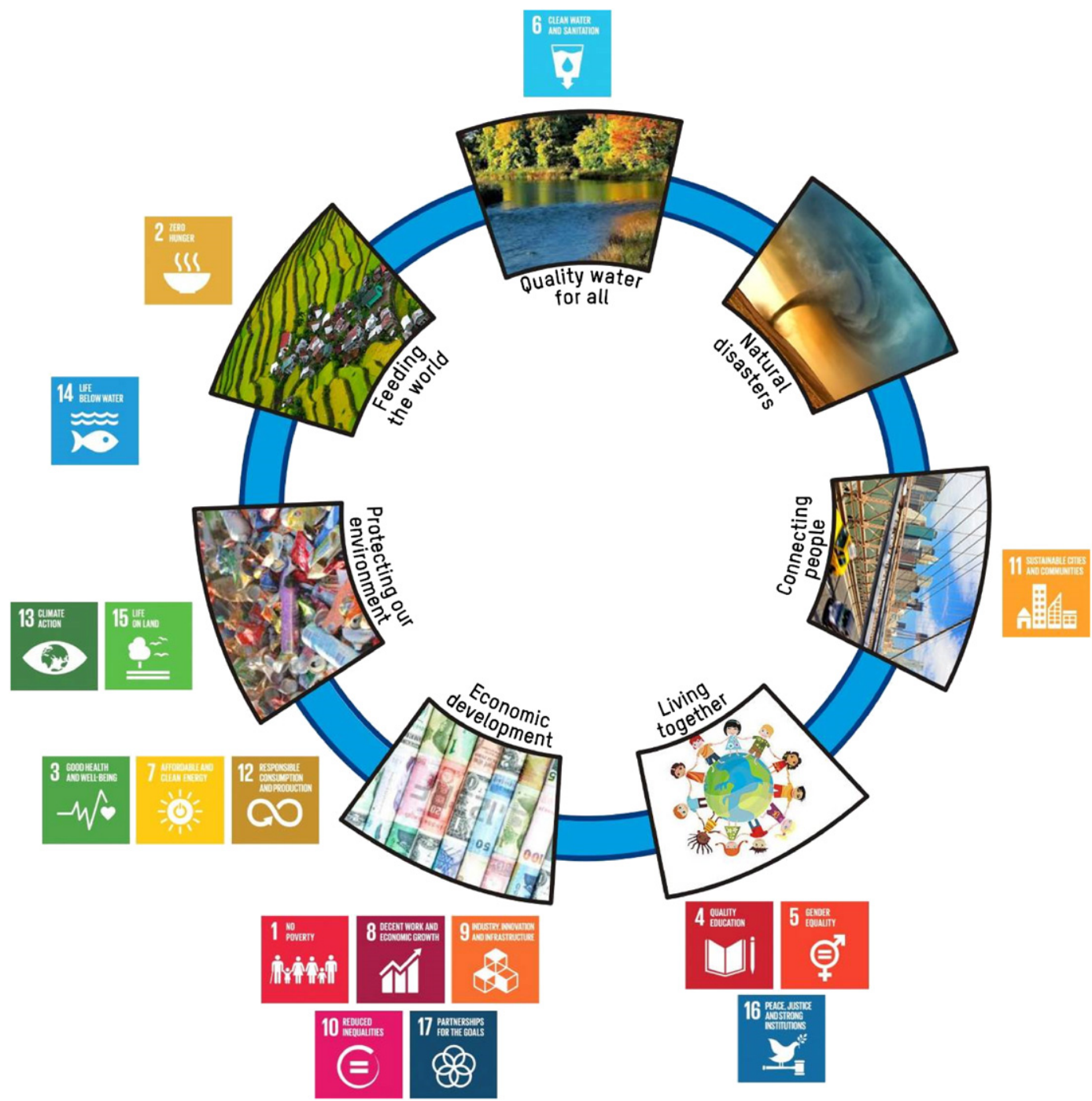

Figure 3. The sustainable development goals and the axes for action of geosynthetics and the IGS for this Giroud lecture

other materials in geotechnical and civil engineering applications. Geosynthetics have pervaded geotechnical engineering to the point that it is no longer possible to practice most forms of geotechnical engineering without geosynthetics. Geosynthetics not only are convenient products but also constitute the basis of a recognised discipline because they perform a variety of functions and because, in many cases, their characteristics are essentially inherent, as opposed to being governed primarily by the interaction with a structure (Giroud 2005). Various families of geosynthetics can be defined depending on the functions they fulfill: barrier first, then drainage, filtration, protection, reinforcement, separation and erosion control.

The barrier function consists of preventing or limiting the migration of fluids. Geosynthetic barriers (GBRs) are geosynthetics that fulfil this function. A geosynthetic barrier is defined in EN ISO 10318 (AFNOR, n.d.) as a low-permeability geosynthetic material used in geotechnical and civil engineering applications to reduce or prevent the flow of fluid through a system. Depending on the material that fulfils the barrier function, GBRs can be grouped into three categories: (i) clay geosynthetic barriers (GBR-C), whose barrier function is implemented by clays, (ii) bituminous geosynthetic barriers (GBR-B), whose barrier function is implemented by bitumen, and (iii) polymeric geosynthetic barriers (GBR-P), whose barrier function is implemented by a polymer.

Other terminologies exist. The word 'geomembrane' is often used to refer to GBR-Bs and GBR-Ps. The terminology 'geosynthetic clay liner' (GCL) may be used to designate a GBR-C. In the Recommended Descriptions of Geosynthetics Functions, Geosynthetics Terminology, Mathematical and Graphical Symbols of the IGS, a geomembrane is defined as a planar, relatively impermeable, polymeric sheet used in civil engineering applications. GCLs are defined as a manufactured sheet assembled from geosynthetic materials and low-hydraulicconductivity earth material (i.e. clay) for use in civil engineering applications.

Because the sole function of a geosynthetic barrier is to provide a barrier to fluids, a geosynthetic barrier must be integrated into a multi-structure system, with each structure performing other specific functions. The main functions that other types of geosynthetics can fulfil are drainage, filtration, protection, reinforcement, separation 
and surface-erosion control. EN ISO 10318 (AFNOR, n.d.) provides the following definitions of six functions of geosynthetics:

- Drainage is the collection and transportation of precipitation, groundwater and/or other fluids in the plane of a geosynthetic material

- Filtration is the restraining of the uncontrolled passage of soil or other particles subjected to hydrodynamic forces while allowing the passage of fluids into or across a geosynthetic material

- Protection is the prevention or limitation of local damage to a given element or material by the use of a geosynthetic material

- Reinforcement is the use of the stress-strain behaviour of a geosynthetic material to improve the mechanical properties of soil or other construction materials

- Separation is the prevention from intermixing of adjacent dissimilar soils and/or fill materials by the use of a geosynthetic material

- Surface erosion control is the use of a geosynthetic material to prevent or limit soil or other particle movements at the surface of, for example, a slope

Various materials within the family of geotextiles and related products can fulfil these six functions. A geotextile is defined as a planar, permeable, polymeric (synthetic or natural) textile material, which may be nonwoven, knitted, or woven and that is used in contact with the soil and/or other materials in geotechnical and civil-engineering applications.

Geotextile-related products are planar, permeable, polymeric (synthetic or natural) materials used in contact with the soil and or other materials in geotechnical and civil engineering applications, and that do not comply with the definition above of a geotextile.

Of the various families of related products, some of which are described in the EN ISO 10318 (AFNOR, n.d.) standard and others in the Recommended Descriptions of Geosynthetics Functions, Geosynthetics Terminology, Mathematical and Graphical Symbols of the IGS, those discussed in this paper are primarily geopipes and geodrains, geogrids, geostrips and drainage geocomposites.

A geogrid is a planar, polymeric structure consisting of a regular open network of integrally connected, tensile elements that may be linked by extrusion, bonding, interlooping or interlacing and whose openings are larger than the neighbouring soil particles.

A geostrip is a polymeric material in the form of a strip no wider than $200 \mathrm{~mm}$ that is used in contact with the soil and/or other materials in geotechnical and civil engineering applications.

A geocomposite is a manufactured and assembled material, with at least one of its components being a geosynthetic product.

Geopipes (or tubes) are perforated or solid-wall polymeric pipes used to drain liquids or gas.

Geosynthetics can be manufactured from various polymers, such as polyethylene (PE), polypropylene
(PP), polyvinyl chloride (PVC) and ethylene propylene diene monomer (EPDM). Bitumen can be alternatively used for geomembranes (Touze-Foltz et al. 2010). Polyester, polyamide and polypropylene are used in the manufacturing of geotextiles. In addition, a number of additives (e.g. chemical compounds) are used in the manufacturing process to ensure the durability of the polymeric materials. The chemical and mechanical characteristics of geosynthetics depend strongly on the type of polymer used, the additive formulation, the morphology, and the application of the geosynthetic (Hsuan et al. 2008).

The objective of the following sections is to illustrate how geosynthetics contribute to ensuring water quality for all, feeding the world, enhancing pollution control, facilitating economic solutions, mitigating natural disasters, connecting people, and helping them to learn to live together according to universal human values.

\section{QUALITY WATER FOR ALL}

By providing the barrier function, geosynthetics, mainly geomembranes, are crucial for the capture, transport, storage, and distribution of freshwater for dams, canals, reservoirs, and pipelines (Koerner et al. 2008). Koerner et al. (2008) suggested a geosynthetics-based freshwater cycle that captures, transports, stores, and distributes freshwater (Figure 4). The following subsections discuss the use of geosynthetics in these various applications and the preservation of water quality.

\subsection{Dams}

A major application of geosynthetics is in dams, which are important because of their impact on safety and the environment (Heibaum et al. 2006; Koerner et al. 2008). Geomembranes have been perhaps the most significant innovation in the field of hydraulic structures in the last 50 years. Their use can avoid problems such as lack of suitable local materials, and they can withstand unlimited water head. Geomembranes are used all over the world

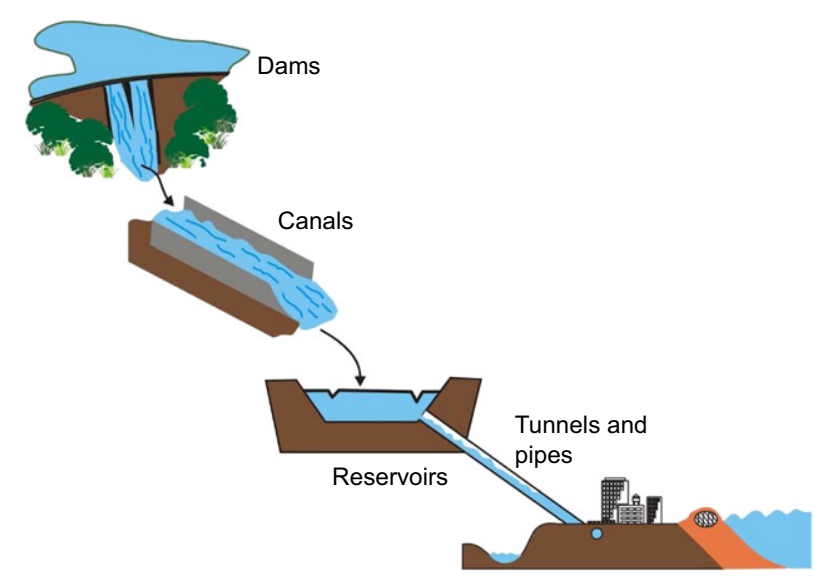

Figure 4. Suggested geosynthetics freshwater cycle for capture, transportation, storage, and distribution of freshwater (adapted from Koerner et al. 2008) 
to waterproof all types of dams: embankment dams, concrete and masonry dams, roller-compacted concrete dams, and so on (Cazzuffi et al. 2010).

During the service life of concrete dams, the upstream concrete degrades, leading to a corresponding increase in leaks. Geomembranes are often used to rehabilitate old concrete dams, in which case the geomembranes are almost always exposed (see Figure 5); they are seldom used in the construction of new concrete dams. Composite geomembranes that combine a geomembrane and a geotextile are the most common for such applications: the geomembrane provides the lining function, and the geotextile reinforces the geomembrane, protects it from mechanical damage by irregularities in the supporting medium and provides drainage behind the geomembrane (Cazzuffi et al. 2010).

In an embankment dam, geomembranes also improve dam safety by reinforcing the lining. They may be placed at two locations: on the upstream slope $(90 \%$ of cases, based on the ICOLD database) (Figure 6), and/or inside the body of the dam ( $10 \%$ of cases). Of the geomembranes installed on the upstream slope, $70 \%$ were covered and 30\% were left exposed (Cazzuffi et al. 2010).

In roller-compacted concrete dams, geomembranes are mostly used in new construction, in which the geomembrane usually lines the entire upstream face of the dam. The roller-compacted concrete mass provides the stability of the dam and the upstream geomembrane renders the structure watertight. The geomembrane can be left exposed or covered (Cazzuffi et al. 2010).

\subsection{Water conveyance through canals}

Canals are used to transport many types of liquids, although freshwater is the most common (Koerner et al. 2017). An important aspect of water management is the distribution of water to farmers via irrigation canals, which are sometimes also used to transport water destined for use as drinking water (Giroud and Plusquellec 2017).

Water is valuable, so water loss and degradation should be avoided. To limit water loss, some canals are lined by covering the bottom and the side slopes of the canal with a barrier. Geomembranes have yet to reach the same level of

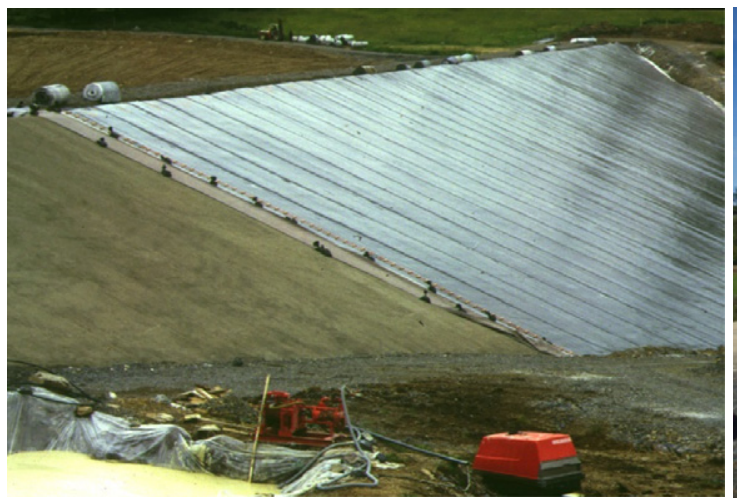

(a)

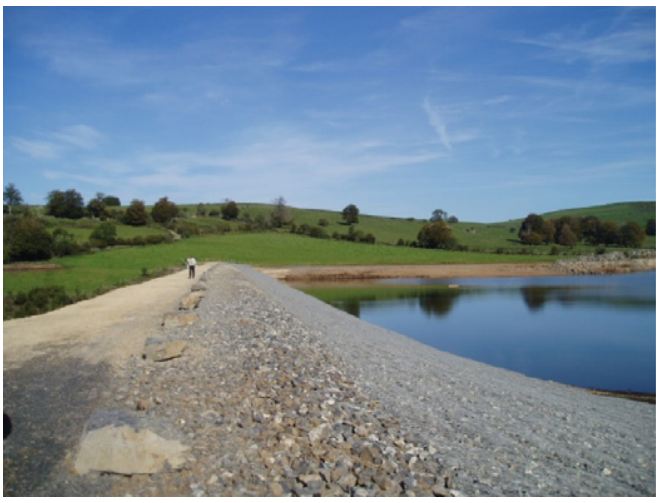

(b)

Figure 5. The Selvet dam (a) during geomembrane installation and (b) after completion and filling (courtesy D. Poulain)

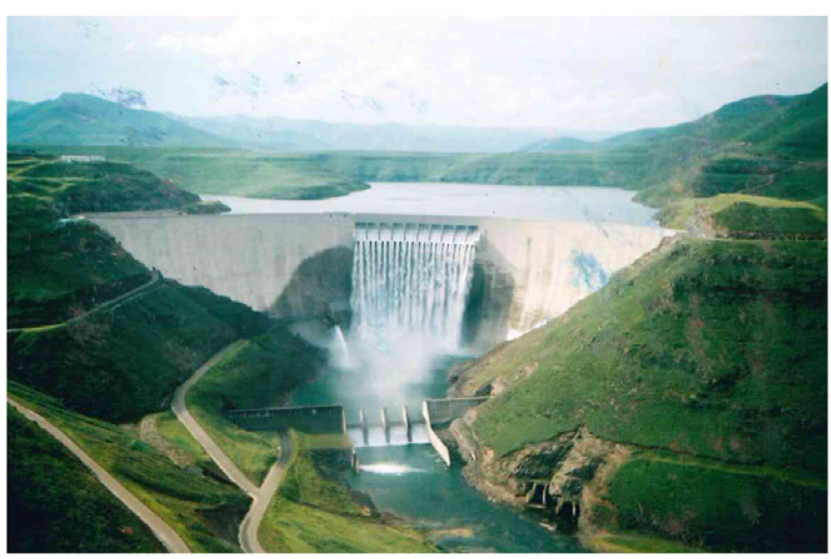

(a)

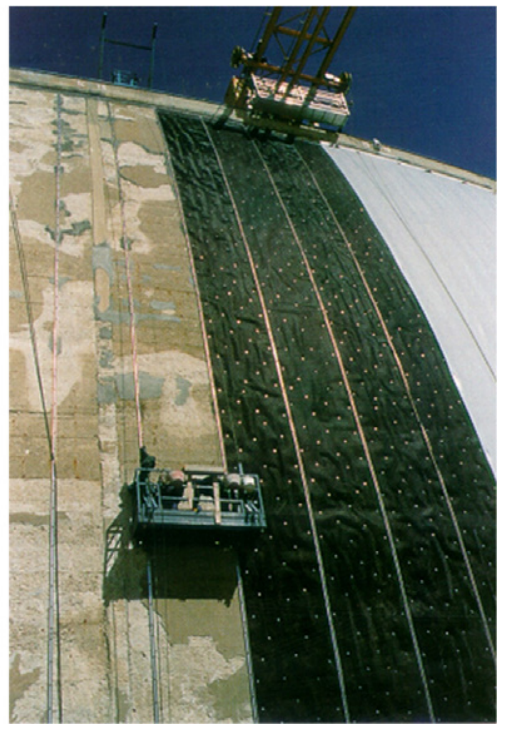

(b)

Figure 6. (a) Katse dam, GIGSA 2016 photo contest (F. Hedrich), courtesy E. Zannoni and Publino dam rehabilitation, courtesy D. Cazzuffi 


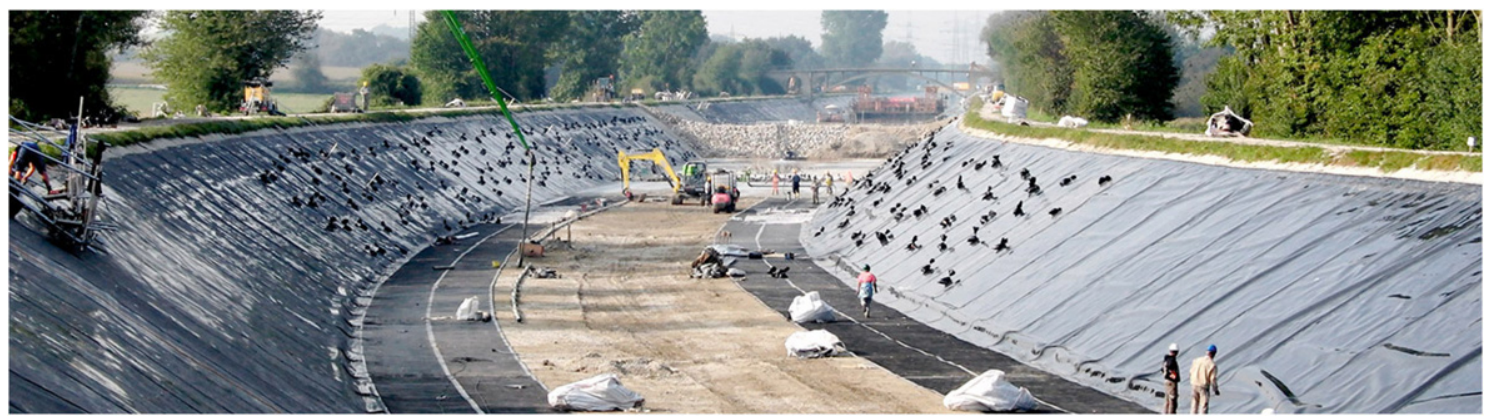

Figure 7. Use of a geomembrane as the lining in a canal (courtesy K. von Maubeuge Naue)

use in canals as in dams: at present, most canals use cement concrete lining (Giroud and Plusquellec 2017).

Data from irrigation canals worldwide show that roughly one-third of transported water is eventually used for irrigation whereas two-thirds is lost through leakage, evaporation, and canal operation (Giroud and Plusquellec 2017). Measurements and analyses show that, shortly after construction, the leakage through a properly installed geomembrane lining (see Figure 7) is at least ten times less than that through a well-constructed cement concrete lining. While in service, if a geomembrane is protected from damage, degradation processes that affect all materials would not modify geomembrane leakage until the actual geomembrane rupture. Given the superior performance of geomembranes in canals, many examples are available of existing cement concrete linings that were repaired by using geomembranes (Giroud and Plusquellec 2017).

\subsection{Water conveyance through hydraulic tunnels}

Hydraulic tunnels are mainly used to convey water, either under pressure or free-flowing, destined for use in power generation and/or in water-supply works. Such tunnels may be lined to prevent water from seeping out and also to prevent water and deleterious chemicals from seeping in. Leaks are detrimental not only in terms of water quantity as the resource becomes scarce but also because they may jeopardise the stability of the ground and of the structure itself. Hydraulic tunnels are usually lined with steel, cast-in-place concrete, or sprayed concrete. Geomembrane systems can be installed as waterproofing for new construction, as a covering, or in rehabilitation projects to repair deteriorated, leaking linings, such as an exposed solution (see Figure 8). PVC has been successfully used in hydraulic tunnels as a barrier against water and gas infiltration and has now become a key element of hydraulic tunnel design. The geomembrane must be backed by a drainage structure to collect the water and discharge it. This avoids external pressure acting inward, which can build up and, in some circumstances, destroy the installation (Cazzuffi et al. 2012).

\subsection{Preserving water quality}

Various polymers are used to manufacture geomembranes for use in hydraulic applications, such as PE, PP, PVC and EPDM. Bitumen can also be used (Touze-Foltz et al.

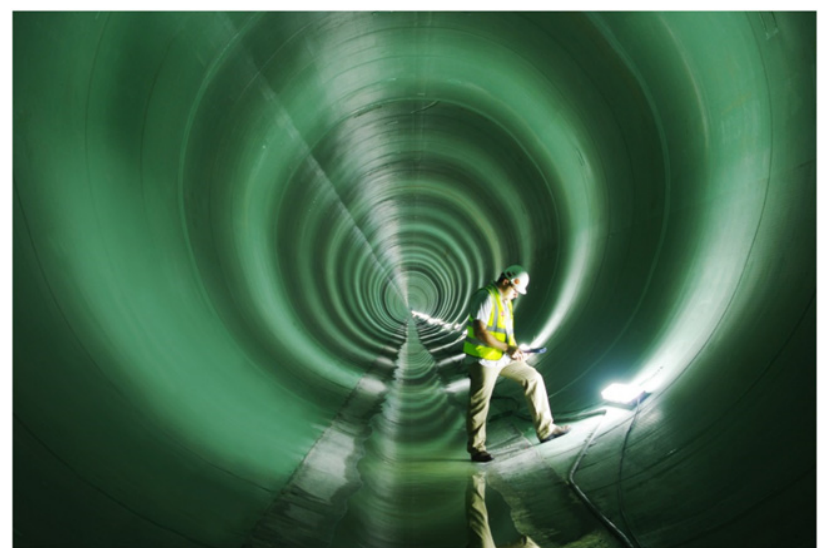

Figure 8. Use of a geomembrane in a tunnel, GIGSA photo contest 2015 (courtesy E. Zannoni)

2010). In addition, a number of chemical compounds are used in the manufacturing process to ensure the durability of the polymeric materials, be they geomembranes or other geosynthetics. Despite the low water solubility of these chemical compounds, studies provide evidence that prolonged contact between geosynthetics and a surrounding aqueous medium extracts them from the geosynthetics (Blanco et al. 2012a, 2012b; Farcas et al. 2012; Pons et al. 2012). Chemical compounds and their degradation by-products represent potential sources of pollution that might impact the surrounding ecosystem and affect public health. To overcome these phenomena, some geomembranes have been developed specifically to resolve potability issues (see Section 4.5.2).

\subsection{Water storage}

\subsubsection{Geomembranes in reservoirs}

Geomembranes are widely used for lining reservoirs or ponds (see Figure 9). The core of a lining system is, of course, the impermeable material (i.e. either a geomembrane or a GCL) (Poulain et al. 2012). Laying a geomembrane directly on the subgrade is generally not recommended. The purpose of draining water from underneath a liner is to prevent water accumulation from a pond, canal, or reservoir and the subsequent uplift of the geomembrane lining system by the backpressure from a raised water table. Under-liner water drainage can be implemented by installing gravel layers, gravel-filled drainage trenches, or geostrips. Depending on 


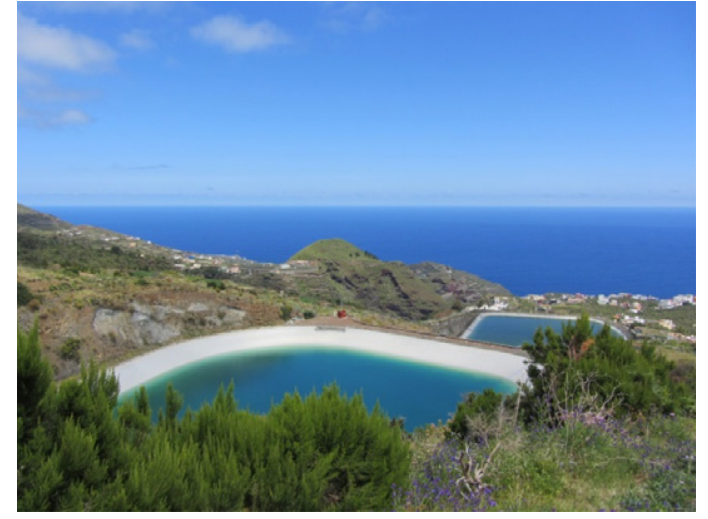

(a)

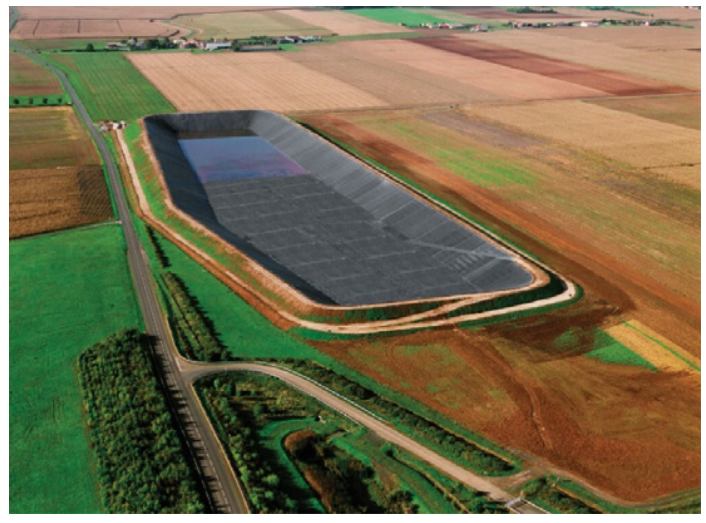

(b)

Figure 9. (a) Reservoirs waterproofed with plasticized PVC-P geomembranes reinforced with polyester synthetic fabrics (Authors: M. Blanco (CEDEX, Spain), A.M. Noval (CEDEX, Spain) \& E. Aguiar (BALTEN, Spain) IGS photo contest 2014) and (b) Large irrigation reservoir lined with EPDM Geomembrane, IGS photo contest 2010 (S. Murray)

the volume of water to be drained, perforated geopipes may supplement gravel-based drainage systems. An additional benefit of under-liner water drainage, especially in containment ponds, is that the drained water quantity and quality may be monitored to detect leaks in the lining system.

Underliner gas drainage may be as important as water drainage. Underliner gas drainage must be undertaken when gas fermentation is a possibility, especially where the total excavation of organic soil is not economically feasible.

Underliner gas and water drainage are frequently implemented as a single system, although state-of-the-art designs now tend to separate these drainages (Poulain et al. 2012).

\subsubsection{Geosynthetic covers for reservoirs}

Numerous reasons exist for covering a freshwater reservoir, such as to minimise evaporation, reduce cleaning maintenance, control algae development, reduce chlorine use, avoid animal excretions, improve safety and discourage intentional pollution (Koerner et al. 2008, Heibaum 2010). Floating geosynthetic covers can provide the desired functions (Sadlier and Taylor 2002; Peggs 2008; Benedetti et al. 2009) (Figure 10a).
Blanco et al. (2017) mention the work by Renz in which reservoirs were covered by using a PE shading mesh inserted between polyamide cables anchored on the reservoir perimeter beam to produce a 'quasi-horizontal cover'. This type of construction is the basis for the current Spanish standard on this topic (Blanco et al. 2017).

Redón-Santafé et al. (2014) designed floating photovoltaic covers for water reservoirs lined with a geomembrane consisting of PE floating modules that adapt to varying water levels in the reservoir by using tension bars and elastic fasteners (Figure 10b). These covers contribute to reducing evaporation and also provide renewable electricity. Combining the photovoltaics in this way also saves land space, which can be used for agriculture (Ferrer-Gisbert et al. 2013).

\subsection{Protecting geomembranes in hydraulic applications}

One of the best ways to prevent the accelerated ageing of geosynthetics, and of geomembranes in particular, is by covering them to limit their exposure to environmental agents such as oxygen, UV radiation, and high temperatures. Overliner layers not only serve this purpose but also prevent liner damage caused by floating or transported solids (e.g. ice, wood), by facility vehicles or machines

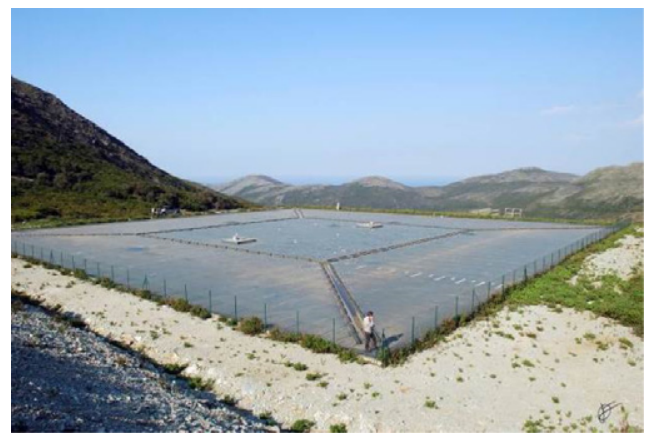

(a)

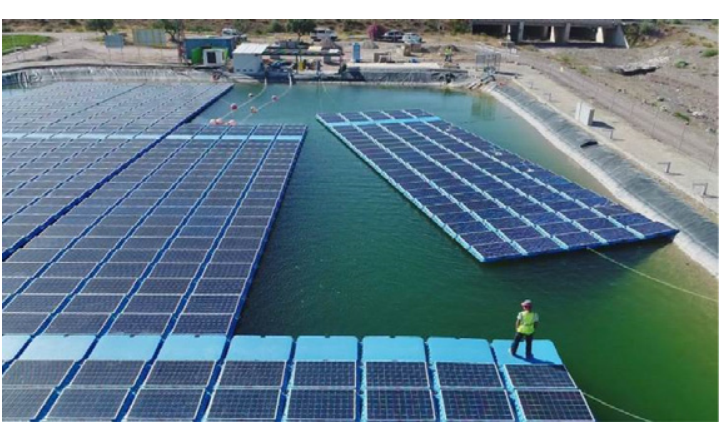

(b)

Figure 10. (a) Full Ersa (Corsica, France) reservoir (from Benedetti et al. 2009) and (b) floating photovoltaic cover (courtesy M. Redón-Santafé) 
(e.g. mobile pumping equipment), by burrowing animals and plant roots, and by vandalism or accidental human intervention. Another purpose of overliner covers is to prevent wind action from uplifting geomembrane lining systems (Poulain et al. 2012).

A common design involves protecting the geomembrane with a geotextile and then covering the geosynthetic with a layer of granular material (IGS n.d. a). Other common designs include concrete covers, precast blocks or slabs, in situ poured reinforced concrete layers or even shotcrete on geotextiles, interlocking concrete blocks, articulated concrete blocks, concrete slabs, geocells or geomatresses or soil and rock protection (Cazzuffi et al. 2010; Poulain et al. 2012).

Data on geomembrane durability in such applications can be found, for example, in Blanco et al. (2018) and Noval et al. (2014).

\section{FEEDING THE WORLD: THE CONTRIBUTION OF GEOSYNTHETICS}

Geosynthetics contribute to agriculture through the capture, storage, and transport of water for irrigation. They also contribute to feeding the world in other ways, as illustrated in the following subsections. This section discusses how geosynthetics protect against soil erosion, how they protect crops and enhance yield, and how they contribute to fish farming and agriculture waste management. It ends with a discussion of trends towards a more sustainable agriculture, which includes considerations of urban areas and avoiding food waste, to show how geosynthetics can contribute to more responsible food production.

\subsection{Protection of soil quality}

Surface erosion develops when soil is exposed to wind and water and is in a transportable state. Erosion may be defined as the wearing-away of any part of Earth's surface by natural causes. Agriculture and aquaculture are affected by erosion in two ways: loss of material (erosion of topsoil, riverbanks or canal banks) and deposition of unwanted material, the latter of which pollutes ponds and waterways or degrades farmland by accelerating the soil erosion (Heibaum 2010). In the context of agriculture, the loss of topsoil hinders the soil's ability to support plant life and the many associated benefits of mature vegetation, which can lead to the increased use of fertilisers, herbicides, and other potential pollutants. Runoff and sediments from such sites can carry unwanted nitrogen and phosphorous into the water system, causing unwanted plant growth that can change the habitat (Allen and Sprague 2011). Rain-eroded soil can silt up a river and significantly impact the waterways, which endangers the fluvial habitat, constrains shipping, and can lead to the need for costly dredging. Intensified sedimentation can increase flood levels because sediment raises the river level as it settles (Heibaum 2014). Erosion countermeasures should be implemented as early as possible in the erosion chain (Heibaum 2010, 2014; Sprague and Sprague 2016).
Vegetation cover is one of the most effective methods to control wind- or water-induced soil erosion (Han and Guo 2017), and natural geotextiles can be used where vegetation is considered to be a long-term solution to slope protection and erosion control (Heibaum 2010; Venkatappa Rao 2016). The use of an organic, decomposable erosion-control blanket can slowly release nutrients for immediate and sustained vegetation growth even in nutrient-poor soils (Allen and Sprague 2011). In addition, such an approach can also help retain pesticides, preventing their further dissemination (Boutron et al. 2009).

Geosynthetics, including the non-biodegradable varieties, can also be used to control erosion in nonagricultural fields. Section 7 discusses the example of coastal-erosion prevention, and the reader is referred to Heibaum (2010) for further details on other applications that will not be discussed here.

Another use of geosynthetics is for the drainage of agricultural land. This is one of the most critical water-management techniques for sustaining productive cropland, which is extremely dependent on the control of water saturation and soil salinisation in the root zone of most crops. In humid regions, drainage controls soil water to provide better aeration, higher temperatures, and easier workability. In contrast, in arid and semi-arid regions, the primary function of drainage is to prevent irrigationinduced water saturation and salinisation of the soil (Ritzema 2016). Modern buried-pipe drains often consist of corrugated flexible and perforated PE pipes wrapped in an envelope, such as a nonwoven geotextile, to improve the permeability around the pipes and prevent the entry of soil particles (Hsieh 2016).

\subsection{Quality of life of animals}

Geotextiles also find a number of applications for livestock. For example, they can be used around farmland as windbreaks, protective fencing or to protect against frost. They can also be designed to protect crops, plants and animals from wind by reducing wind speed (Hsieh 2016), or to reinforce surfaces subjected to high livestock traffic. For example, fall and spring rains can render cattle areas dangerously muddy for the herds (Hsieh 2016), and the use of geotextiles in areas of high livestock traffic substantially reduces the unhealthy and hazardous footing conditions for livestock. Furthermore, the cost of installing geotextiles is about one third that of installing concrete surfaces.

\subsection{Fish farming}

Since the 1980s, aquaculture - the aquatic version of industrial agriculture - has become the fastest-growing source of fish worldwide. Some observers see aquaculture as an opportunity to reduce the pressure on wild fish stock while addressing the growing imbalance between fish production and food requirements for an expanding world population (Heibaum 2010) (see Figure 11). Aquaculture has been directed to the rational use of land and water resources to ensure harmony between fish farming and the environment. For example, closed tanks have been 


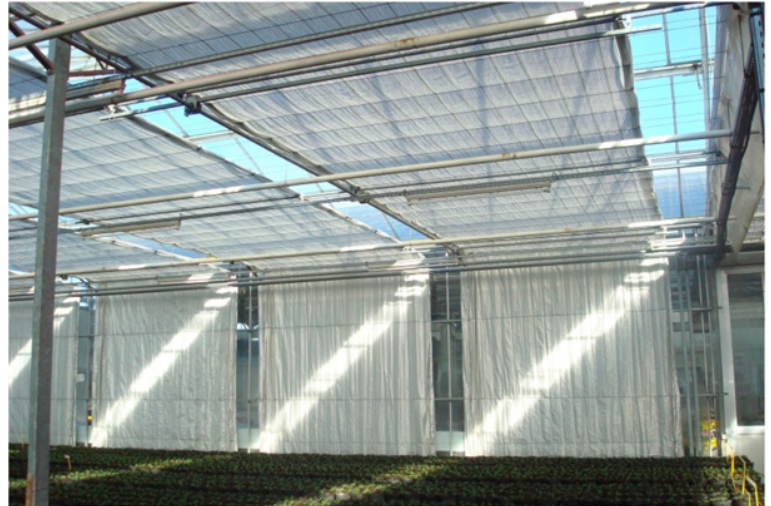

(a)

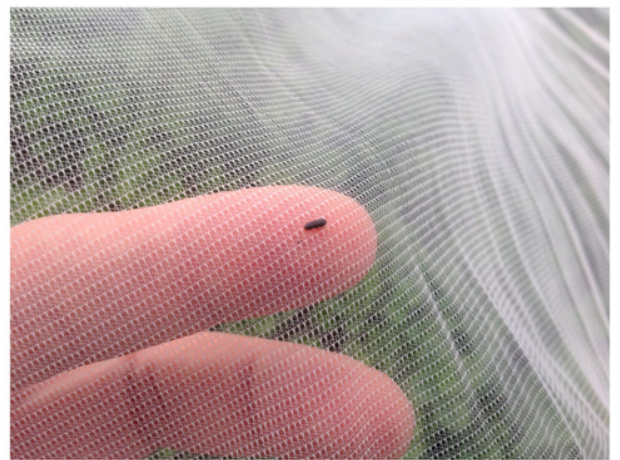

(b)

Figure 11. (a) thermal screens providing shadow inside a greenhouse and (b) pest control net (courtesy F. Moinerau, Texinov)

demonstrated as technically feasible ways to grow salmon (Heibaum 2010). These systems eliminate the escape of solid waste into the marine environment, contamination of the area under the tanks, escapes from the rearing facility and marine-mammal deaths due to interaction with farmed fish and nets. In addition, water quality is improved because the smooth surface of the geomembrane facilitates pond cleaning (Hsieh 2008, 2016).

In aquaculture, geotextiles can be used to protect geomembranes from puncture, but also to cover the soil and limit its erosion when geomembranes are not used (Saengrungruang and Boyd 2014; Hsieh 2016).

\subsection{Management of agricultural waste}

\subsubsection{Manure storage}

If properly managed and applied responsibly, animal manure can be a good fertiliser (Hsieh 2016). However, manure can also become a contaminant if it mixes with surface water or groundwater, and animal-waste lagoons contribute to the pollution of groundwater and surface water. With the increasing concern over pollution and the concomitant increase in government legislation, the use of geosynthetics has become more common. In particular, exposed geomembranes, geomembranes with soil cover and GCLs with soil cover are currently being used to seal animal-waste lagoons. In addition, geotextiles and geonets are used for both protection and gas transmission
(Barrington et al. 1998; IGS n.d.b). Some regulations furthermore require closures (i.e. a top cover) to (1) reduce the propagation of odours or germs, (2) to reduce emissions of greenhouse gases by collecting the methane produced by anaerobic degradation of manure and (3) to prevent dilution to maintain the agronomic value of the manure (DeGarie et al. 2000; Ng et al. 2009; Touze-Foltz 2014).

\subsubsection{Sludge management}

Sludge dewatering tubes are increasingly popular for agricultural or livestock remediation (see Figure 12a). A geotextile tube is made of an extremely resistant geosynthetic wrapper filled by hydraulic pumping. The structure is built on site and filled in its final position (Palma et al. 2016). Sludge dewatering tubes can also be used to manage aquaculture waste (Hsieh 2016) or animal waste (Lawson 2006, 2008), as further discussed in Section 6.5.

\subsubsection{From agriculture waste to energy}

In addition to providing a local source of energy, the recovery of methane removes a source of atmospheric methane. Anaerobic digesters serve to rapidly decompose animal waste in a controlled environment, thus allowing the recovery and use of methane-rich biogas that is then used to fuel combined heat and power generators that

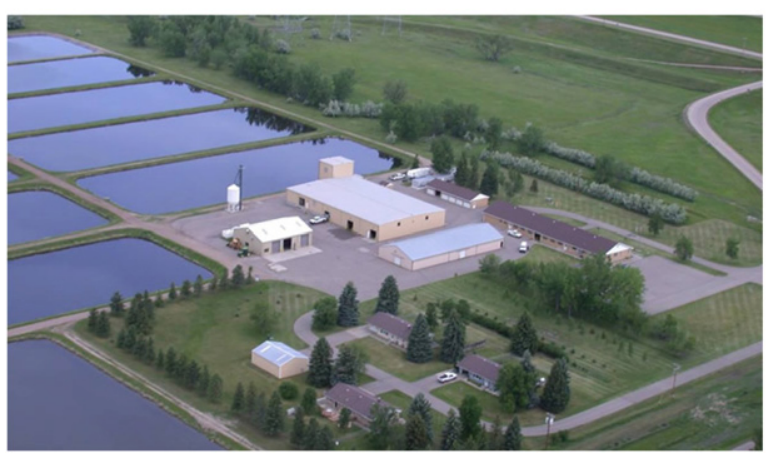

(a)

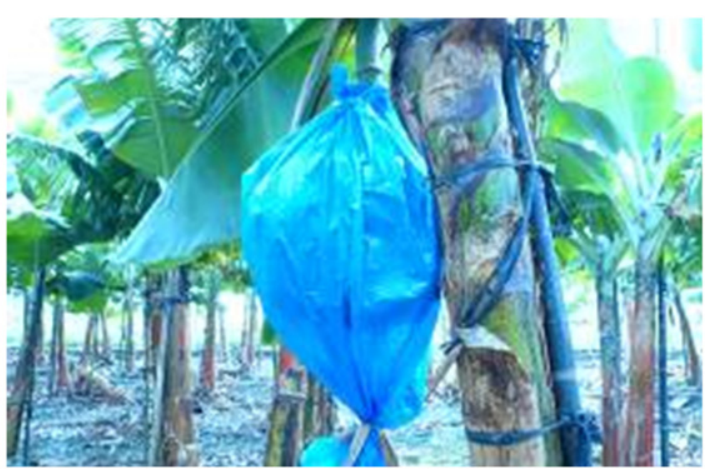

(b)

Figure 12. (a) Garrison Dam National Fish Hatchery (courtesy Rob Holm/USFWS) and (b) Floating net cages (Hsieh (2008), with the GRI allowance for use from the Proceedings of the GRI-21 Conference on Agriculture and Aquaculture, Cancun, Mexico, 5 March 2008) 
produce on-farm electricity, heating for agriculture processes and domestic hot water (Land and Water 2007). Anaerobic digesters use both bottom-lining systems comprising geosynthetics and flexible cover systems (see Figure 12b). The number of operating digesters is rapidly increasing worldwide as government funding becomes increasingly available for farm installations (IGS n.d.b).

\subsection{Towards a more sustainable food production}

When used to cover the soil, geotextiles and geomembranes help to promote germination and plant growth. By regulating the quality and quantity of light reaching the crops, netted $\mathrm{PE}$ shading geotextiles allow farmers to control growing conditions, manipulate growth patterns, and protect crops from excessive sun. At the same time, they protect against wind, hail and other extreme weather (Figure 13a). Geosynthetics thus contribute to improving food production in both quantitative and qualitative terms (Hsieh 2016).

To improve fruit quality and control pests, fruit can be covered with plastic or geotextile bags (Figure 13b). For example, covering grapes with nonwoven bags is very effective for reducing bird and insect damage to the crop (Hsieh 2016). This is all the more important because food appearance is a factor that contributes to excessive wasted food.

The use of geosynthetics thus helps to control crop growth, thereby easing farmer workload, extending harvest periods, and avoiding an oversupply connected to a limited harvest period and the concomitant price drops and waste (Heibaum 2010). Given the magnitude of greenhouse gas emissions from the agricultural sector, this application of geosynthetics is crucial because strategies to reduce food loss and waste would make a strong contribution to mitigating global climate change (Porter and Reay 2015).

\section{POLLUTION CONTROL}

This section first discusses how to minimise the impact of contaminant transport from solid-waste facilities and mining installations, and then discusses the use of geosynthetics for treating sludge and sediment. Producing renewable energy from waste or sunlight is also discussed.

\subsection{Minimising impact of contaminant transport from solid-waste facilities to underground}

Landfills are an essential part of an integrated wastemanagement strategy, and not least because they provide the only terrestrial sink for hazardous substances that would otherwise be dispersed into the environment. Over the last four decades, the practice of landfilling has evolved significantly, with fully engineered facilities now subject to stringent regulations to protect the environment (Touze-Foltz et al. 2008).

Several types of lining systems can be used for waste containment, with the goal being to limit contaminant migration to levels that have a negligible impact on the environment. With these lining systems, there are associated drainage systems to reduce the hydraulic head of leachate on top of the liner ('leachate' is the rainwater that has charged itself with pollutants while flowing through waste and can be harmful to the environment).

The bottom barrier serves to minimise the migration of contaminants from the facility, so the environmental impact of the facility is intimately related to its design and long-term performance (Rowe et al. 2004). The European legislation on waste disposal (OJEC 1999) requires that landfills be situated and designed so as to prevent pollution of the soil, groundwater, or surface water and to ensure efficient collection of leachate. The landfill base and sides must consist of a mineral layer that satisfies certain hydraulic conductivity and thickness requirements, which have a combined effect on the protection of soil, groundwater and surface water. Where the geological barrier does not naturally meet the required conditions, it can be completed artificially and reinforced by other means that give equivalent protection. This is where GCLs can be used.

However, the mineral liner is not used in isolation. In fact, many modern landfill barrier systems require a leachate collection system and a geomembrane (often a high-density PE, or HDPE, geomembrane because of issues related to contaminant transfer and durability) over either a compacted-clay liner or a GCL (Touze-Foltz et al. 2016). Composite lining systems formed by the

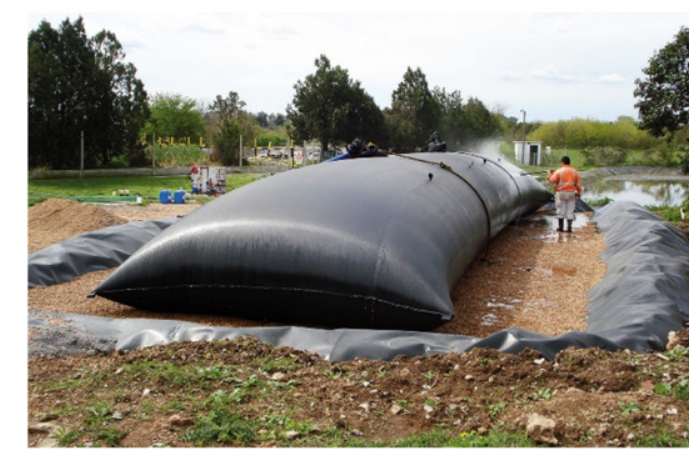

(a)

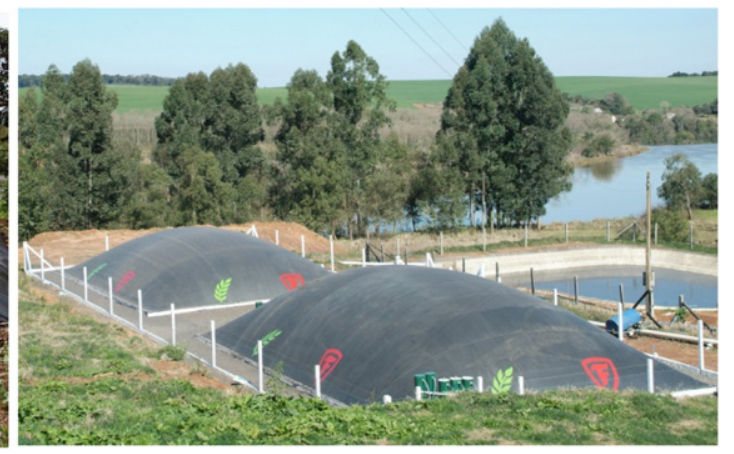

(b)

Figure 13. (a) Containment for sludge treatment, IGS photo contest 2014 (A. Teixera), and (b) anaerobic digester lined and capped with EPDM Geomembrane, IGS photo contest 2010 (S. Murray) 


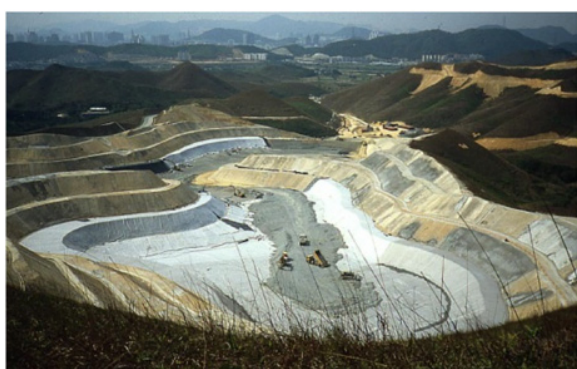

(a)

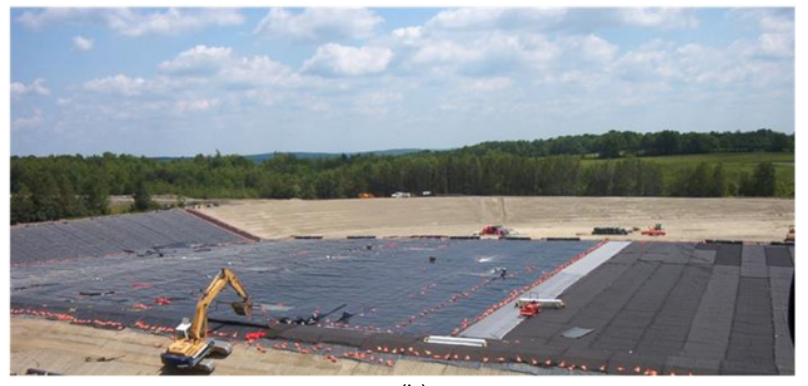

(b)

Figure 14. (a). The Honk Kong landfill, winner French chapter of IGS photo contest 2015 (courtesy T. Gisbert, Arcadis) and (b) landfill cell construction, IGS photo contest 2010 (C. Burdick)

association of a compacted-clay liner or a GCL and a geomembrane provide redundancy, which in turn provides additional protection. Composite systems thus improve containment performance and, ultimately, environmental protection (Rowe 1998; Rowe and Brachman 2004; Touze-Foltz et al. 2006; Jones and Dixon 2011; Jones 2015) (see Figure 14).

However, the benefits of using geosynthetic liners as part of a barrier system may not be fully realised if the geomembrane is physically damaged: geomembranes form excellent barriers to fluids only if there are no holes in the geomembrane (Rowe 1998). Geomembranes may develop holes during installation, although most holes can be prevented by applying quality control (Rowe 1998; Touze-Foltz et al. 2008). In practice, different types of protective layers (e.g. geotextiles, sand layers, combinations of geotextiles and sand layers, sand-filled cushions, rubber mats, layered geotextile composites) are introduced between geomembrane and coarse drainage gravel to prevent damage to the geomembrane (Touze-Foltz et al. 2008; Brachman and Sabir 2013).

\subsection{Preventing water infiltration into waste body and gas migration to atmosphere}

The aim of final covers for landfills is to limit, but not necessarily prevent completely, the infiltration of rainwater into the waste and thereby to control leachate production and minimise gas emissions from the landfill (see Figure 15). For example, to achieve these goals, European regulations require that the landfill cap includes a gas-drainage layer, a lining system, a water-drainage

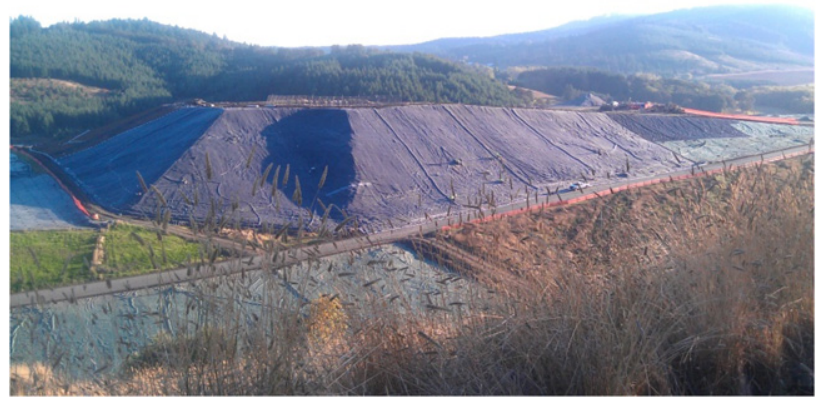

Figure 15. EPDM Geomembrane rubber temporary landfill cover used over a twenty year span, IGS photo contest 2014 (W. Johnson) system, and a topsoil cover. The general objective is to reduce the flux of water and gas. Toward this goal, various semi-permeable or impermeable cover alternatives are possible, provided they meet the performance objectives in terms of liquid and gas flow into and out of the landfill, reduce the waste hazard, and have geosynthetic lifetimes longer than the waste-hazard period.

Compacted clay liners, GCLs, and geomembranes are thus not the only materials that can be used as landfill caps. Drainage geocomposites, including either a geofilm or a continuous HDPE draining core with overlaps to allow water flow, can satisfy the demand for alternative cover systems for non-hazardous waste (Meydiot and Lambert 2000; Faure and Meydiot 2002; Fourmont and Arab 2005; Fourmont et al. 2009a, 2009b).

\subsection{The case of radioactive waste following the 2011 Tohoku earthquake and tsunami}

The 2011 Tohoku earthquake in the western Pacific off the east coast of Japan induced a large-scale tsunami that together produced a catastrophe in Japan with massive loss of human life, and massive damage to buildings and infrastructure. One casualty was the Fukushima Daiichi nuclear power plant, which was seriously damaged. The damage led to three reactors overheating, with the resulting hydrogen-gas-fuelled explosions releasing large amounts of radioactive materials into the atmosphere, to be subsequently deposited by rain over the adjacent land (Inui et al. 2012). A number of temporary storage sites were commissioned to store soil and waste generated by the decontamination work. The geomembrane technical committee of the IGS Japanese chapter developed procedures for (1) selection and installation of storage containers to prevent polluted water from leaking out of storage sites, (2) designing and building structures and selecting appropriate barrier materials, and (3) inspecting the seams of cover geomembranes (Shimaoka et al. 2014). Currently, over 16,000 temporary storage sites exist and incorporate a bottom geomembrane liner, piles of bagged soil or waste and a top cover to prevent rainwater infiltration into the waste (see Figure 16).

\subsection{Geosynthetics in mining applications for metal production}

Mining is the backbone of many economies around the world, including in developed countries such as Australia. 


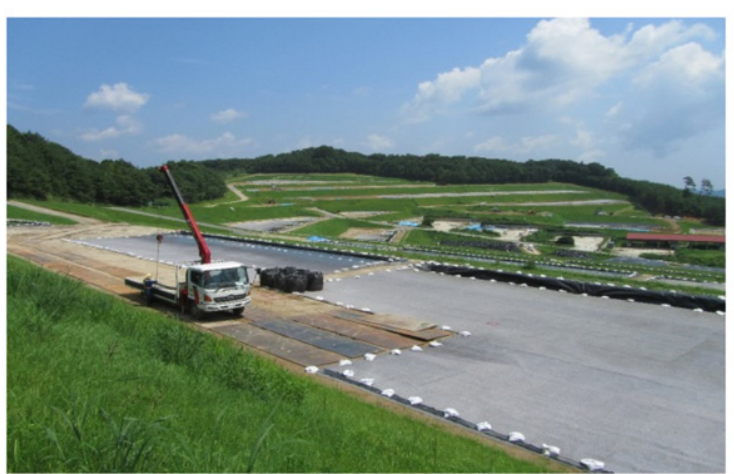

(a)

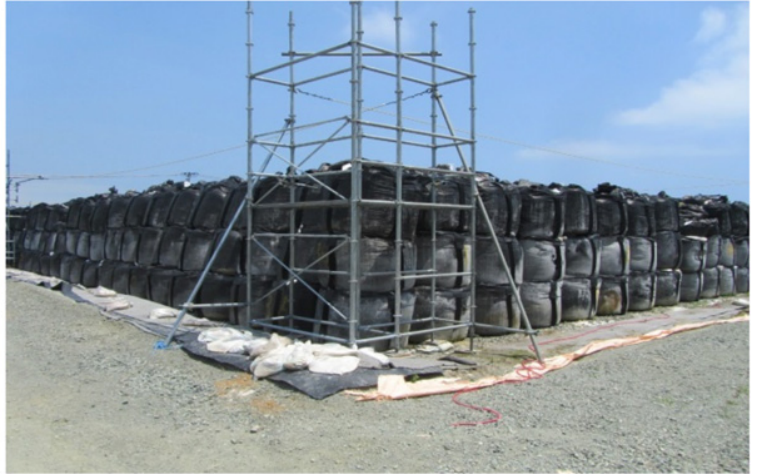

(b)

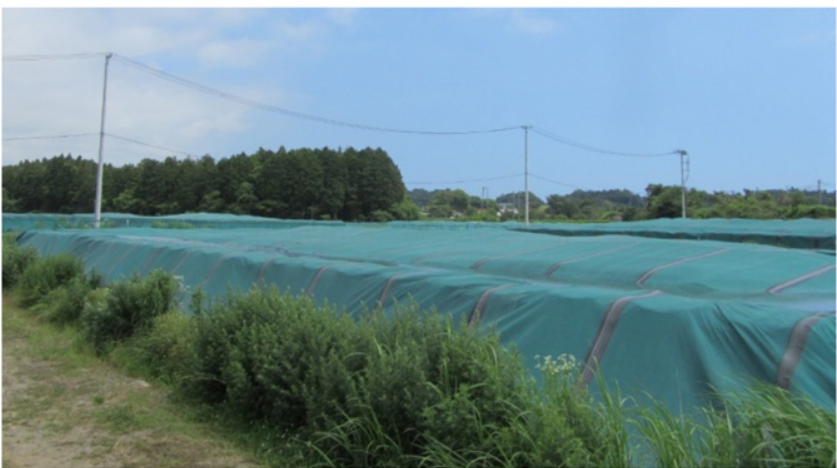

(c)

Figure 16. (a) placement of bottom geomembrane, (b), piles of bagged soils or waste, and (c) geomembrane cover on bags (courtesy T. Katusmi)

In many developing countries, mining provides over $50 \%$ of export earnings (Bouazza 2013). The purpose of incorporating geosynthetic barriers into a modern mining operation is to reduce the environmental risks associated with contaminant migration off site and to improve the recovery of mine water either for reuse or to extract the product from solution (Bouazza 2013). Lining systems are designed to meet requirements that are similar to those of bottom-lining systems in landfills, with a particular focus on the specific chemical and mechanical environments in mining applications (Bouazza 2013). Another specificity is that, because of the stable slope, the geomembrane has no puncture protection (Touze-Foltz et al. 2008). Geosynthetic materials are now commonly used in lining systems for heap leach pads (HLPs), tailings storage facilities (TSFs), waste rock or overburden storage facilities, and lined ponds and channels (see Figure 17).

\subsubsection{Heap leach pads}

HLPs are lined facilities into which ore is placed. A leaching solution is applied to the ore to dissolve the minerals contained therein. The leaching solution depends on the type of ore to be processed and may consist of a strong acid (e.g. sulfuric acid) or, to heap leach gold and silver, a dilute cyanide solution (Touze-Foltz

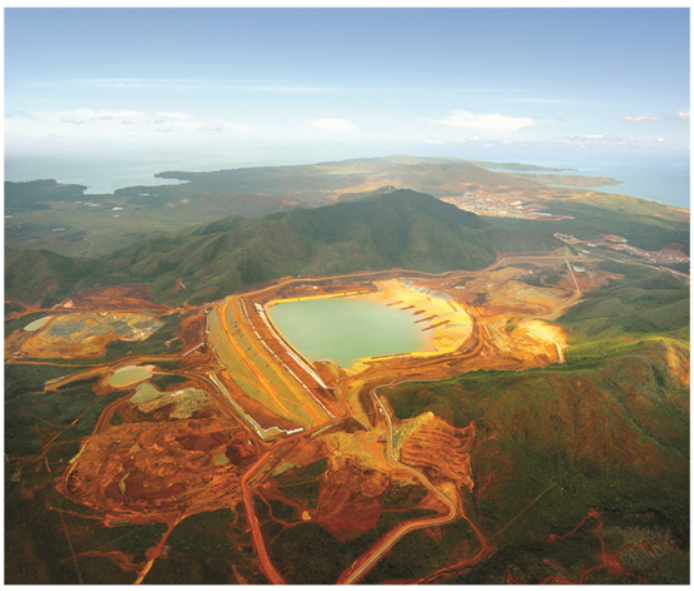

(a)

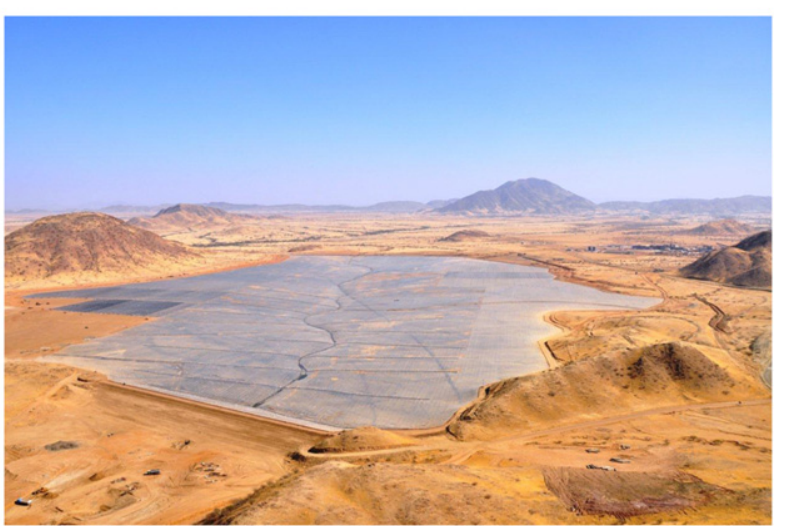

(b)

Figure 17. (a) Nickel mine, New Caledonia, IGS photo contest 2014 (A. Sasu), and (b) tailing dam, GIGSA photo contest 2015 Geosynthetics International, 2021, 28, No. 1 
et al. 2008). As the leaching solution gradually percolates through the ore, it dissolves the precious metals, producing what is known as a 'pregnant solution'. Because the mining product in this case is the pregnant solution, losses through the underliner system must be minimised and, if at all possible, eliminated, so that recovery is maximised (Bouazza 2013). The geomembrane retains the chemical solution used to dissolve the minerals from the ore and allows the leaching solution to be collected and refined. An important consideration when designing an HLP is thus the leach-solutioncollection system. The most common HLP solutioncollection systems consist of geopipes embedded in a drainage layer. Depending on the design of and the conditions within the HLP, the solution-collection systems may also include geotextiles, corrugated and perforated (single- and double-walled) pipes, perforated or nonperforated HDPE pipes and geodrains (Touze-Foltz et al. 2008).

\subsubsection{Tailings storage facilities}

When water is used in the extraction process to concentrate valuable substances from ore, the waste produced is a sludge that is generally called 'tailings', which are basically solid particles dispersed in water. TSFs are engineered structures constructed to impound tailings. Depending on the geochemistry of the tailings and process solution, the tailings may be stored within a geosynthetic-lined TSF.

A continuous or intermittent drainage layer may also be placed over the liner to enhance tailings consolidation or provide internal drainage for the TSF. Geosynthetic materials such as geopipes, geotextiles and geodrains are often incorporated into the design of the drainage system.

\subsubsection{Fluid fine tailings}

Oil sands, phosphate exploitation, and alumina refining all generate very fine-grained sludge $(\mathrm{d} 80<20 \mu \mathrm{m})$ with a high clay content. The oil-sands industry generates a sludge waste called fluid fine tailings (FFTs). FFTs have a high clay content and contain 70-80 wt $\%$ water and $1-3 \mathrm{wt} \%$ residual bitumen, which makes them particularly difficult to dewater (Mikula et al. 1996; Allen 2008; Jeeravipoolvarn et al. 2009). The two key problems caused by FFTs are the large volume of material and its very poor geotechnical properties, which are both caused by its high water content (Mikula et al. 1996; Snars and Gilkes 2009; Farkish and Fall 2013). Dewatering FFTs is a preferred path to increase the shear strength of the tailings and reduce the volume of material to be contained, which reduces the risk of failure, reduces the footprint and minimises water consumption (Farkish and Fall 2013). One solution is to lay, during filling, an electrokinetic geocomposite within the FFT disposal area to dewater the sludge (Gastaud et al. 2015, 2017), induce a hydraulic gradient and drive the water out (Faure et al. 1993). Applying an electric field across the sludge layers produces electro-osmosis within the sludge, leading to water migration (Jones et al. 2008; Fourie and Jones 2010).

\subsubsection{Mining waste storage}

During the mining process, waste rock or overburden is removed to provide access to the ore. The overburden materials are often placed in a dedicated facility that is engineered to provide stability and drainage. Liner systems for overburden storage facilities are used if a possibility exists that poor-quality seepage will develop from the overburden as a result of percolation of rainwater through the material and subsequent reactions with minerals in the overburden, thus creating leachate.

Overburden storage facilities often include solutioncollection systems to collect and route seepage to ponds or sumps for further analysis, treatment if required, and discharge. Such facilities usually consist of collection drains excavated into the subgrade. The drains are surrounded with filtration geotextiles to prevent the migration of fines from the overburden and from the foundation into the collection pipe (Touze-Foltz et al. 2008).

\subsection{Dewatering of waste and contaminated sediments}

Many industries use water for processing and for the movement and storage of byproducts and waste, which results in large volumes of liquid or slurry-like materials. The treatment and disposal of sewage sludge, for example, is one of the most problematic issues affecting wastewater treatment in developed countries (Glendinning et al. 2006). A preliminary treatment significantly reduces the volume of the slurry waste and renders it manageable for handling, transport, and disposal (Lawson 2006, 2008). Such treatment commonly consists of dewatering. Geotextile tubes for sludge dewatering offer significant cost savings and are environmentally friendly: they have a relatively small footprint, which allows for a greater number of dewatering sites, and optimise land use when only a limited area is available for containment and dewatering (Lawson 2006, 2008; Hsieh 2016).

Geotextile tubes provide an ideal medium for the dewatering of slurry-like waste streams and contaminated sediments such as municipal waste, agricultural waste, food and food-processing waste, industrial and mining waste and contaminated sediments (Lawson 2006, 2008, 2014). Effective dewatering requires a geotextile-tube dewatering platform that is installed at the base of a stable barrier to support the geotextile-tube dewatering units and prevent loss of effluent water from the tubes into the foundation. Above the barrier, which can be a geomembrane, a drainage blanket is installed to facilitate full-circumferential drainage from the geotextile tube (Lawson 2006, 2008).

\subsection{Renewable energy}

An increasingly popular practice is non-penetrating mounting of photovoltaic modules on contaminated land sites (e.g. landfills, mines); more specifically, on geomembrane caps that are already used on such sites to contain pollution (Brooks et al. 2011). Solar energy cover is a composite system that integrates flexible photovoltaic laminates (i.e. flexible solar panels) with an enhanced-exposed geomembrane cap (see Figure 18). 


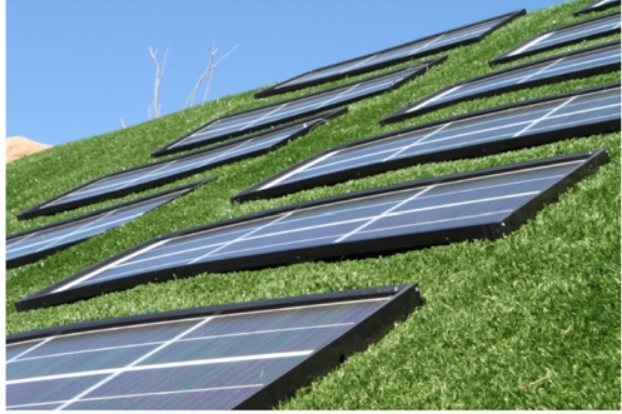

(a)

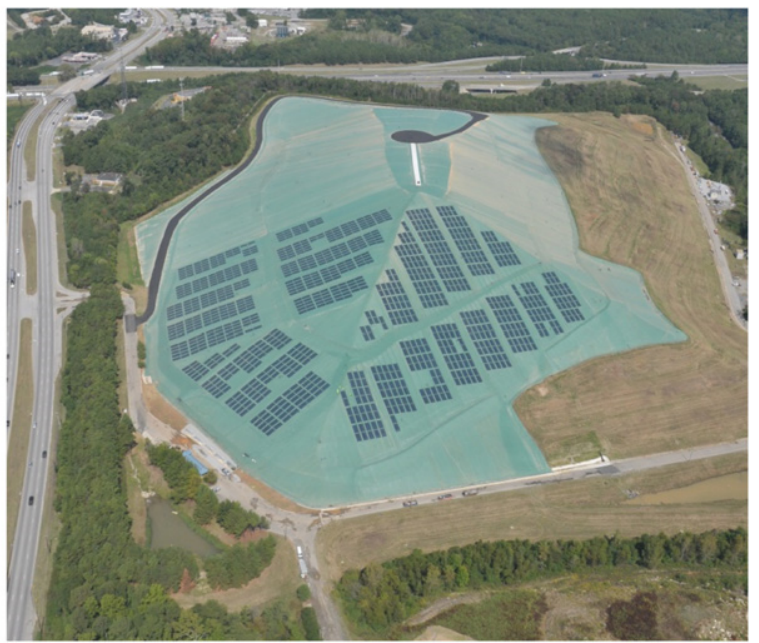

(b)

Figure 18. (a) Solar growing from grass, STRS welded with AGRU LLDPE membrane with Closure Turf grass on top installed on an unengineering slope at 55 degrees, IGS photo contest 2010 (N. Barba) and (b) Solar cells installed on an exposed Geomembrane cap at the Hickory Ridge landfill near Atlanta Georgia (courtesy Carlisle Energy)

Other technologies involving rigid solar panels constitute an alternative approach to turn landfill sites into sources of solar power (Alexander 2010). Based on the various examples presented, work is under way to demonstrate that these systems contribute to energy independence and to reducing the unsustainable dependence on fossil fuels (Alexander 2010). Furthermore, the benefits in terms of public perception and of moving toward a more sustainable source of energy, though not quantifiable at present, are nevertheless significant (Alexander 2010).

As is the case for agriculture (see Section 5.4.3), the recovery of methane is also a concern in environmental applications, whether from landfills containing biodegradable waste, from leachate lagoons ( $\mathrm{Ng}$ et al. 2009), or from wastewater-treatment plants where covered anaerobic ponds promote the sedimentation of wastewater solids and their anaerobic decomposition into methane (Craggs et al. 2015). The landfill cover enhances biogas capture for energy recovery, while simultaneously preventing the emission of greenhouse gases and the associated odour (Craggs et al. 2015). For municipal lagoons, DeGarie et al. (2000) report that biogas production and use should pay for the cover systems.

\subsection{Mitigation of climate change through the use of geosynthetics}

Dixon et al. (2017) state that two categories of actions are required to tackle climate change and its effects: (i) mitigation to reduce greenhouse-gas emissions and (ii) adaptation. Geosynthetics can contribute to mitigation by reducing greenhouse-gas emissions from construction and operating infrastructure. In fact, the ecological advantages of construction methods using geosynthetics are well known: the use of geosynthetics rather than soils can dramatically reduce emissions compared with excavation, transportation and the placement of soil.

The sustainability of materials and processes is commonly assessed by calculating the $\mathrm{CO}_{2}$ emissions generated. Although this is a simplification, the ease of calculation encourages comparisons between solutions and makes such assessments accessible, transparent, and repeatable so that the $\mathrm{CO}_{2}$ emitted can more easily be inventoried for comparison with industry, national, and international targets (Dixon et al. 2016).

Such calculations were made for various applications of geosynthetics, including filtration (Ehrenberg et al. 2012; Laidié et al. 2012), stabilisation of foundations (Ehrenberg et al. 2012; Elsing et al. 2012), construction of landfill drainage layers (Ehrenberg et al. 2012; Werth et al. 2012), construction of soil-retaining walls (WRAP 2010; Bouazza and Heerten 2012; Ehrenberg et al. 2012; Fraser et al. 2012; Damians et al. 2017, 2018; Russell et al. 2017), implementation of slope protection (Bouazza and Heerten 2012; Heerten 2012), construction of roads (Bouazza and Heerten 2012; Heerten 2012), implementation of capping systems for landfills (Bouazza and Heerten 2012), engineering slopes by using an electrokinetic geosynthetics treatment (Jones et al. 2014) and the use of geosynthetics to reinforce bridge abutments (Beauregard et al. 2016). The results of these studies show that structures that incorporate geosynthetic layers tend to have a lower embodied carbon (EC) value compared with structures that use conventional granular solutions. The use of geosynthetics results in massive improvements to $\mathrm{CO}_{2}$ savings as opposed to nearly all alternative civil engineering materials used.

The past few years have seen an improved mastery of techniques of life-cycle analysis in the field of geosynthetics. The latest calculations made by Dixon et al. (2016) and Damians et al. $(2017,2018)$ are indicative of the progress made in this field, in which an ever-more constructed standard approach has been evolving by using EC values representative of geosynthetics (Raja et al. 2015) and by comparing the EC values for entire construction solutions. Thus, results are recognised and trusted when they claim that the use of geosynthetics significantly reduces the environmental impact. 


\section{MITIGATION OF NATURAL DISASTERS}

Although water is the origin of life, it can also threaten life when it breaks out of its normal boundaries: all modes of human life require a balance between water and ground (Heibaum 2014). In areas of the world particularly exposed to the threat of climate change, the question of protection against water gains importance as population density increases. Geosynthetics can make a significant contribution to adaptation, specifically by improving the resilience of communities and infrastructure against extreme climate disasters, such as flooding, landslides and droughts (Dixon et al. 2017).

\subsection{Preventing coastal erosion}

Coastal erosion may be defined as the continued retreat of coastline over time. The advance and retreat of coastlines is a natural phenomenon that has always existed and that, over time, has moulded the coast into its current shape (Palma et al. 2016). However, in addition to the perennial natural causes are now added anthropogenic causes. The continuous growth of construction near coastal areas increases human exposure to natural hazards. Given that the causes of erosion cannot be eliminated and that the increased vulnerability to hazards does not prevent people from settling on the coast, we must adopt measures that ensure the safety of goods and people without disregard for the natural benefits of coastal areas. Dykes (also referred to as levees) are one such measure and serve to protect developments from flooding. Artificial reefs and submerged breakwaters are other measures and consist of underwater structures that disperse wave energy offshore, thus reducing the wave energy arriving at the coastline and thereby reducing their erosion action (Lawson 2016). The environmental awareness that has grown over the last decades of the 20th century and into the 21st and the scarcity of rock sources in particular for building breakwaters had led to a search for alternative materials such as geotextiles (Palma et al. 2016), which have a long history of use in marine engineering to prevent erosion.

When used to line containment units, geotextiles hold sand fill, which results in a stable mass-gravity unit that is erosion resistant and structurally sound (Lawson 2016). They answer the growing concern over the environment and the concomitant restrictions in mining and quarrying. In addition, by allowing the use of locally available natural materials, high transportation costs and the associated pollution are avoided (Venkatappa Rao 2016). An interesting element mentioned by Lawson (2016) is that artificial reefs and submerged breakwaters made from geotextile units provide a safe, injury-free environment for humans in close proximity to populated beaches (see Figure 19). Geotextile containers also attract an abundance of marine plants and life soon after construction, making such artificial reefs a prime fish habitat.

\subsection{Flood protection}

A flood is an overabundance of water that submerges land that is usually dry (Heibaum 2014).

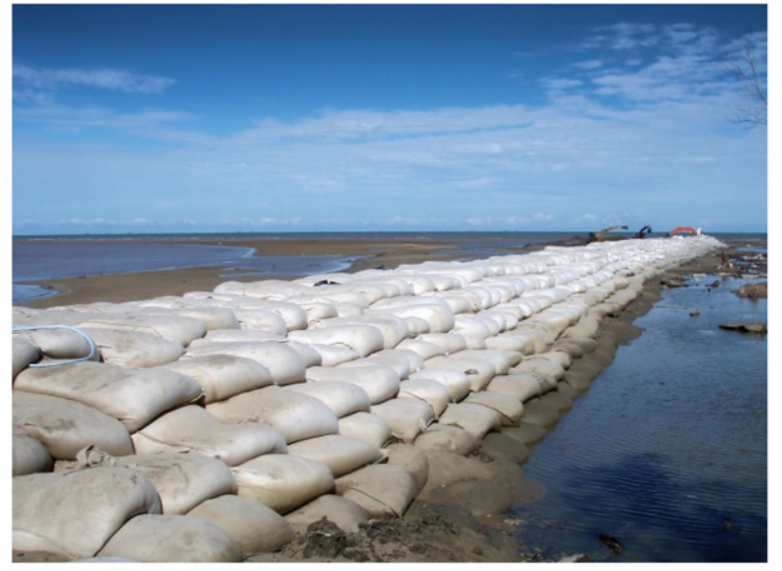

(a)

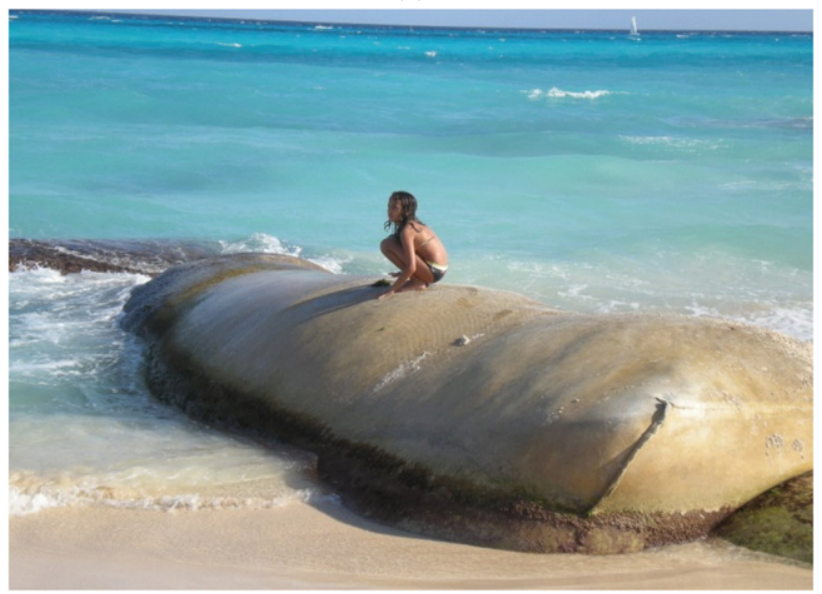

(b)

Figure 19. (a) Sei Samboja Groyne, East Kalimantan to control sea sediment transport, IGS photo contest 2014 (H. Sumantri) and (b) Comtrac coastal protection, Cancun, Mexico, IGS photo contest 2010 (S. Lothspeich)

River valleys, like the coast, attract settlements. Various works such as dams, levees, and canal systems can be undertaken to minimise the damage inflicted by flooding. Most dykes and flood-protection dams are less than 10 to $15 \mathrm{~m}$ in height and usually take the form of longitudinal barriers. Geosynthetics have also proven useful in these structures. Note that different measures are required for permanent versus temporary flood protection.

In river structures, whether to rehabilitate existing dams or construct new ones, geosynthetics serve the following purposes (Brandl 2010, 2011): (1) as horizontal, vertical and inclined filter and separation elements; (2) sealing of dyke slopes by installing geomembranes on the water side; (3) reinforcement of fill, crest zone and access road for dyke defence; (4) surface-erosion protection; (5) vertical cutoff walls; and (6) protection against digging animals.

For temporary flood protection, Brandl $(2010,2011)$ recommends the use of sandbags for local stabilisation if a risk exists of hydraulic failure of a dam or dyke by seepage uplift or internal erosion or piping. Sheets of geotextile filters covered with granular material can also be used for large critical zones.

Although less frequently used, geotextile tubes to mitigate the wave-breaking process in meandering rivers or to fill broken sections of dams have proven very suitable 
as low-crested submerged structures to reduce the incident-wave energy at shorelines.

\subsection{Landslide prevention and soil reinforcement}

Landslides are defined as a form mass wasting that includes a wide range of ground movements such as rockfall, deep failure of slopes, and shallow debris flows. Landslides are caused by natural or man-made factors or a combination thereof, such as weak soil conditions, high rainfall and seepage, erosion by streams and rivers, vibrations caused by earthquakes, increased vegetative load, wind load, excavation, increased loading, vibrations caused by traffic, or deforestation (Shukla 1997). Landslides may be controlled somewhat by improving drainage conditions, growing more vegetation on slopes, providing proper retaining structures (Figure 20) and using some recently developed ground-improvement techniques such as soil reinforcement (Shukla 1997; Mohri et al. 2009; Cuomo et al. 2020).

Geosynthetics can be very attractive for works involving embankments built on soft foundation soils. They have proven to be a cost-effective alternative to other foundation-stabilisation methods, such as dewatering, excavation and replacement with select granular materials, or to the use of thicker stabilisation aggregate layers or chemical stabilisation (Zornberg 2017b). Basically, geosynthetic layers can serve as reinforcing materials or can accelerate the process of consolidating soft subgrade. Reinforcement also reduces the consumption of fill material because it minimises or avoids local failure mechanisms caused by construction equipment during transport, spreading, and compaction of the fill material (Palmeira 2012).

In addition to reinforcing geogrids, randomly distributed fibres within the soil mass or piled embankments can be used to increase soil strength (Heibaum 2014). More detailed information about these design approaches can be found, for example, in Palmeira (2012).

\subsection{Slope stabilisation and reinforced soil walls}

Slopes can be natural or man-made, and several natural and man-made factors contribute to soil instability
(Shukla 1997). The advent of geosynthetic reinforcement materials has brought a new dimension of efficiency to the design and construction of reinforced slopes and retaining walls. Geosynthetic reinforced walls are now a mature and proven technology in almost all countries (Allen et al. 2002; Bathurst 2014). Geosynthetic-reinforced slopes are generally compacted fill embankments that incorporate geosynthetic horizontal layers as tensile reinforcement to enhance stability. The use of geosynthetics for slope stabilisation allows earth works to be downsized by changing their geometry and even allows the use of soils with average mechanical properties (Shukla et al. 2012). Geotextiles, both woven and nonwoven, and geogrids are now being increasingly used to reinforce steep slopes (Shukla et al. 2012).

More complex structures are geosynthetic reinforced soil (GRS) retaining walls with full-height rigid (FHR) facings, which are characterised by the following features: (1) the use of a FHR facing that is cast in place by using staged construction procedures, (2) the use of a polymer geogrid reinforcement for cohesionless soil to provide good interlock with the soil, (3) the use of a composite of nonwoven and woven geotextile for nearly saturated cohesive soils to facilitate both drainage and tensile reinforcement of the backfill, (4) the use of relatively short reinforcement, and (5) the use of low-quality on-site soil as backfill if necessary (Tatsuoka et al. 1997).

\section{ECONOMIC ANSWERS PROVIDED BY GEOSYNTHETICS}

The use of geosynthetics in civil engineering applications often provides financial benefits by reducing the cost of imported materials, reducing waste and generally providing more efficient use of resources compared with traditional solutions based on soil, concrete and steel (Jones 2015). In 2014, during the 11th International Conference on Geosynthetics in Berlin, Christopher (2014) gave an original and unequalled review of cost savings provided by geosynthetics in which he focused on the construction of civil engineering projects such as roads, embankments, retaining structures, erosion-

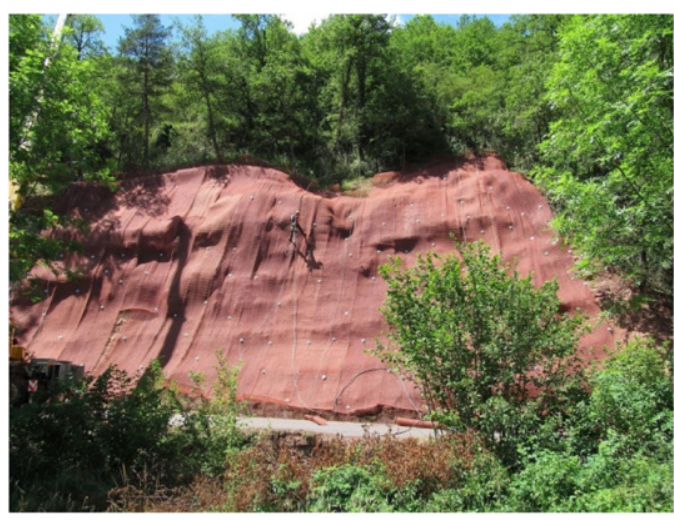

(a)

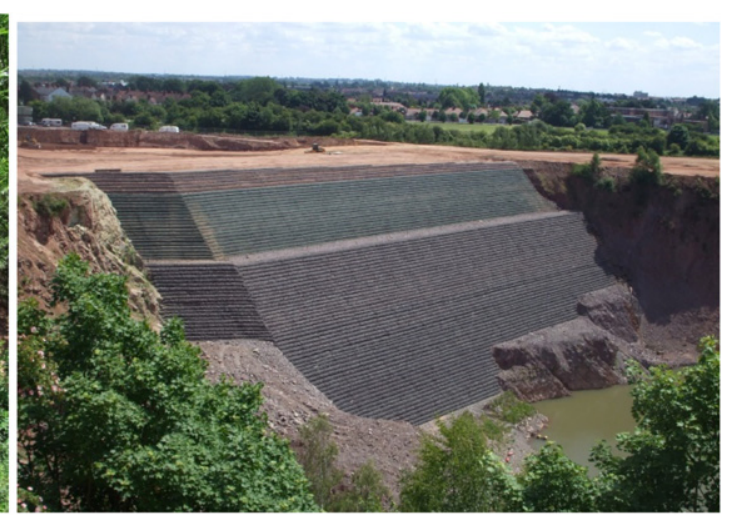

(b)

Figure 20. (a) Landslide prevention by using geosynthetics for erosion control. Winner French Chapter photo contest 2017 (courtesy Stéphane Pavlesk) and (b) Large reinforced soil structure just completed, IGS photo contest 2010 (P. Assinder) 
control features, drainage systems, reservoirs, and waste-containment systems.

The use of geosynthetics in roadways is well documented for their long-term performance and the following four types of cost savings: (1) reduction of the quantity or need for select soil material, (2) easier and/or accelerated construction, (3) improved long-term performance, and (4) improved sustainability (this latter point is discussed in detail in Section 6.7).

In many cases, the economic benefit is such that the use of geosynthetics is now the standard practice. This is the case for the following scenarios.

(1) Geotextile filters in drainage applications: in this case, the geotextile reduces the size of edge-drain trenches; the cost savings from the reduced excavation volume and the reduced filter-material volume are significantly greater than the cost of geosynthetics.

(2) GRS: GRSs are almost always less expensive than conventional reinforced concrete and gravity-type earth-retaining systems due to lower overall system material costs (in general by $25 \%$ to $50 \%$ ).

(3) Geosynthetic reinforced soil slopes (RSSs): RSSs are cost-effective alternatives for new construction where a steeper slope is desired. When repairing slope failure, the new slope will be safer, and reusing the slide debris rather than importing higher quality backfill may result in substantial cost savings. RSSs can be constructed at about half the cost of GRSs and thus provide a viable economic alternative.

(4) Geosynthetics used for constructing reinforced soil embankments: for weak soils, geosynthetics used in reinforced soil embankments reduce the displacement of foundation soil that would be required to construct unreinforced embankments. The amount of fill saved often offsets the cost of the reinforcement, and additional cost savings are usually achieved through expedient embankment construction when using geosynthetic reinforcement.

(5) Geosynthetics in waste and containment systems: the most significant cost savings related to material replacement are for geosynthetics used in landfill applications and, to a lesser extent, other containment applications such as reservoirs. In fact, the savings come not just from the cost difference between the geosynthetic and the replaced material but, more significantly, from the value of the volume of space saved by using very thin geosynthetic materials to replace the thicker geological barrier, where allowed by regulations.

\section{LIVING TOGETHER}

\subsection{Connecting people}

Roads and railways are of the utmost importance to the development of any country (IGS n.d.c). Not only economic growth and climate action but also social development are heavily dependent on infrastructure
(UN 2015). The following subsections show how geosynthetics contribute to improve road networks, railways and bridges.

\subsubsection{Using geosynthetics to improve road networks}

Paved roadways are designed and constructed to permit safe, efficient, and economical transport of passengers and commercial traffic. To attain these objectives, pavement distress induced during roadway construction and operation must be kept within acceptable limits. Due to the systematic traffic of heavy vehicles, climate conditions and the mechanical properties of the materials used in road construction, the lifetime of road pavements may be considerably shorter than expected (Zornberg 2017a).

In this scenario, geosynthetics are effective in the following ways (Zornberg 2017a).

(1) Mitigating reflective cracking in asphalt overlays: over time, the repeated loading and the varying climatic conditions cause cracks and joints in the previously existing pavement to reflect into the new overlay, a phenomenon called 'reflective cracking'.

A reflective crack propagating through new pavement overlay may make the new overlay susceptible to water intrusion and early failure. In this case, geosynthetics reinforce, separate, stiffen and act as a barrier (Zornberg 2017a) (see Figure 21).

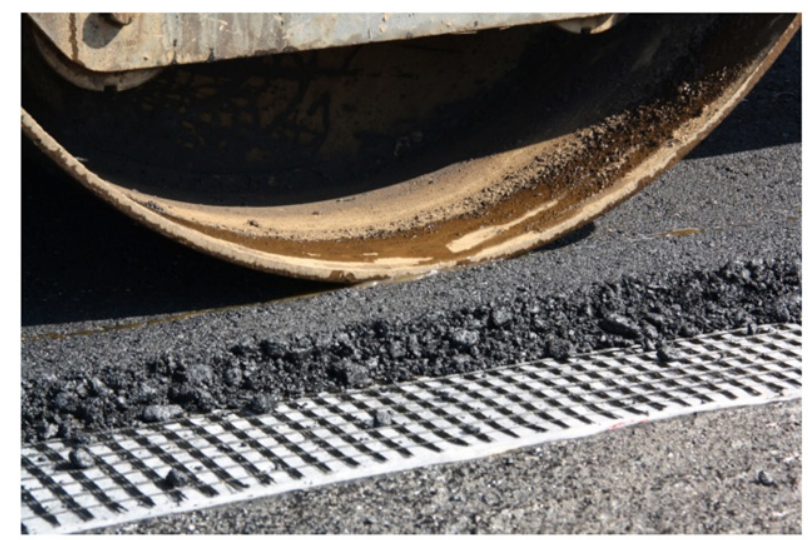

(a)

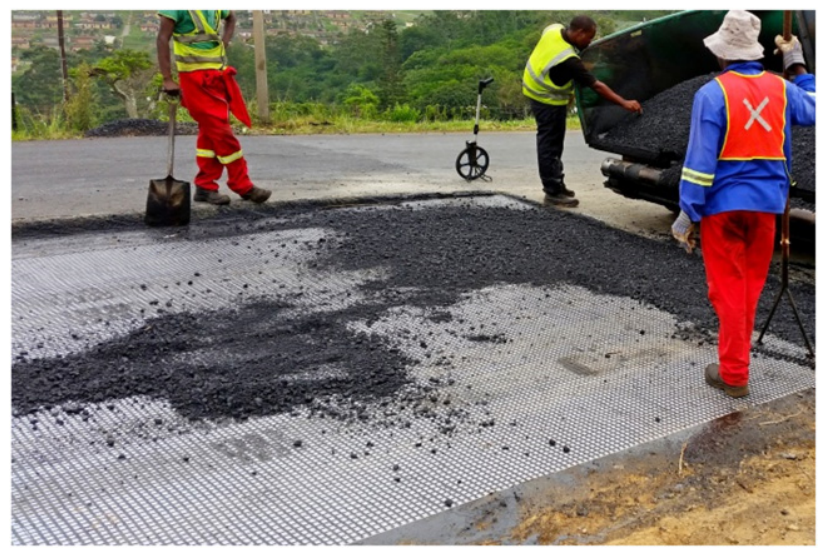

(b)

Figure 21. Asphalt reinforcement (a) GIGSA photo contest 2015 and (b) GIGSA photo contest 2017 
(2) Ensuring separation: a major cause of failure of roadways constructed over soft foundations is the contamination of aggregate base material by the underlying soft subgrade soil. Even a small amount of fines contaminating a granular layer can negatively affect the granular layer's structural response because of a reduced base-layer thickness, which reduces road lifetime (Zornberg 2017a). A geotextile placed between a fine-grained subgrade and a coarse-grained base layer can minimise contamination of the base layer by fine particles pumped up from the subgrade under repeated traffic loads (Bourdeau and Ashwamy 2012) and allow the base layer to remain 'clean', which preserves its strength and drainage characteristics (Perkins et al. 2012).

(3) Stabilising soft subgrades of roads: the reinforcement provided by geosynthetics is often essential to allow initial construction. The presence of a weak subgrade may lead to localised shear failure in the subgrade, which creates significant deflections in the various overlying layers of the roadway (Zornberg 2017b).

(4) Ensuring lateral drainage from roadways: in roadways, water flow may be induced by pore-water pressure generated in the subgrade by traffic loading. In the absence of a proper filter, fines contained in the subgrade may be carried by the pore water into the base. The key to this application lies in the ability of the geosynthetic to filter fines without becoming clogged (Perkins et al. 2012). Drainage is also important because the presence of moisture in the base and/or subgrade layers of a pavement is detrimental, compromising the mechanical properties of these soils (Zornberg 2017b). Adequate drainage of a pavement should extend the lifetime of the pavement system by a factor of two to three with respect to a similar pavement with inadequate drainage (Perkins et al. 2012).

Geotextiles and geogrids have also been used successfully to separate, filter, drain, or reinforce soils of unpaved roads (Bourdeau and Ashwamy 2012).

\subsubsection{Connecting people via railways}

Railways are also important for connecting people and require improvements in some locations. For example, about $7000 \mathrm{~km}$ of railway in India (out of $60000 \mathrm{~km}$ ) sit on a weak foundation, causing ballast penetration and resulting in multiple losses, such as extra maintenance costs for track and rolling stock, speed restrictions, higher fuel consumption, and passenger discomfort. Rehabilitation and strengthening of such tracks can help to eliminate speed restrictions (Venkatappa Rao 2016) (see Figure 22). In this context, geotextiles ensure separation between the various layers to prevent fines in the subgrade from being pumped up into the granular layers, which would reduce the strength and the drainage capacity of these layers. Separation of the various layers is thus one function of geosynthetics in this context. Good drainage is critically important to avoid track deterioration and can be augmented by using a drainage geocomposite (IGS n.d.d).

Finally, the key functions of sub-ballast are drainage and stress absorption to dissipate stress from wheel loads to acceptably low values at the subgrade layer. To achieve this, a geotextile can separate the subgrade from the overlying material to prevent ballast contamination. Furthermore, a geogrid can provide lateral confinement and thereby reduce shear stresses in the subgrade soil below.

\subsubsection{Bridges}

The GRS integral bridge technology combines the technologies of integral bridge and GRS retaining walls with FHR facing. The first step to building a GRS integral bridge is to build a pair of GRS walls. After deformation of the supporting ground and backfill of the GRS walls, FHR facings are constructed by casting in place concrete on the wall face wrapped with a geogrid reinforcement (see Figure 23). Finally, a continuous girder is constructed with both ends integrated into the top of the FHR facings. The girder is also connected to the top of an intermediate pier, or piers, if constructed (Tatsuoka et al. 2014).

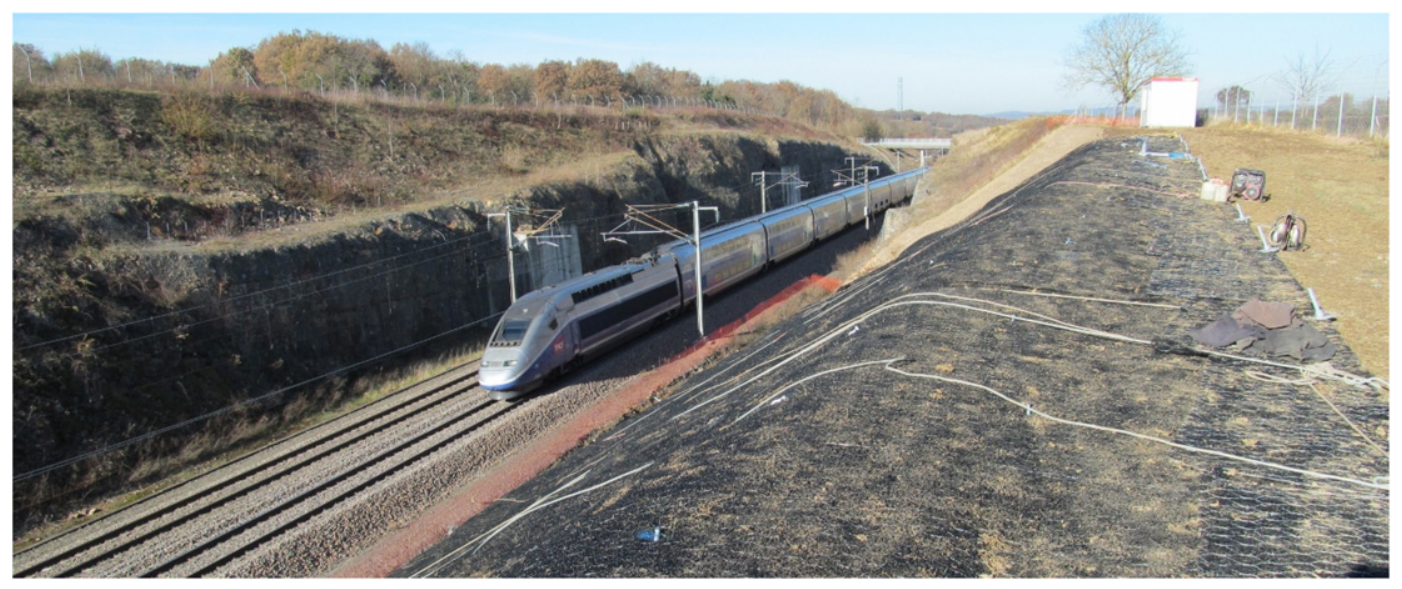

Figure 22. High speed train in France, tracks, ballast and protection of the railway, French chapter of IGS photo contest 2015 (S. Cazottes) 


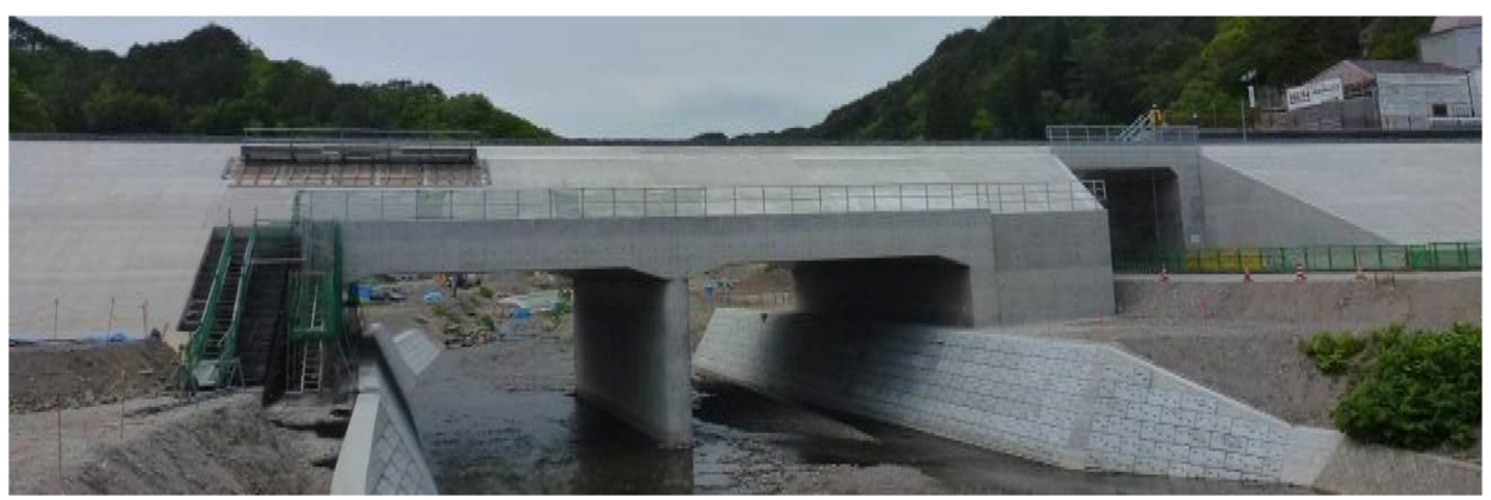

Figure 23. GRS integral bridge, Shima-no-koshi, Sanriku Railway, 20 May 2014 (courtesy F. Tatsuoka)

GRS integral bridges have essentially no bumps in the approach fills and suffer no structural damage to the facing from seasonal thermal expansion or contraction of the girder, whereas their stability against floods, tsunamis and seismic loads is very high. These features are attributed to the staged construction of FHR facing, which is firmly connected to the geogrid layers (Yonezawa et al. 2014). GRS integral bridges are now the standard for railways in Japan. They are appropriate options for railway and road bridges in many places worldwide.

\subsection{Towards a new global society}

Science and technology have had an undeniable effect on the world. Today, no sphere of human life is unaffected by science. The previous sections have emphasised this phenomenon by focusing on how developments in geosynthetics science and engineering affect land management and allow physical connections to be established between people. Although we may all agree on the essential role science and technology play, we are increasingly less sure of the criteria to adopt to guide its applications. Science itself is unable to dictate the human qualities required to guide our use of Earth (Thuan 2013). This is where values are of primary importance.

\subsubsection{Definition of values}

What are values? A compass to think and a guide to act. They are characterised not only by the fact that systems of values endure, but also by the fact that they influence not only individuals but also societies. Values have worth; they represent what is not negotiable for an individual or a group of individuals (Lenoir 2012).

As a French person, I am influenced by national philosophers often mentioned in this Giroud lecture. The readers are of course encouraged to expand their thinking beyond the preliminary approach developed here and incorporate their own philosophy and world view.

Lenoir (2012) suggests that six values could serve as a basis on which to build a new civilisation on a planetary scale, not based solely on market logic but on what, under various forms, has formed the basis of civilisations around the world and that is shared by all: beauty, truth, justice, respect, love and freedom. Through a dialogue of cultures, a rewording of values should help to build a global civilisation based on universal values incorporating local singularities. But what meaning can be given to these six values? And how are they expressed in the cosmos of geosynthetics? A brief overview is given in the following sections.

\subsubsection{Beauty}

In India, beauty is considered to reflect the perfect ordering of the World, as is the case for Chinese or Greek thinkers. If a formal beauty exists that can be attested to by art, architecture, and natural shapes, then a form of beauty also exists that is ideal and transcendent and that goes beyond the canons of beauty to make it approach the supreme divinity. Kant (2015) writes that, as we speak about beauty, we enter the field of universality. Beauty is absolute represented in a relative manner, infinity represented in a finite way, eternity represented in a temporal way (Comte-Sponville, 2006).

\subsubsection{Geosynthetics blend with local environment}

Some authors in the field of geosynthetics make explicit references to beauty. For example, some structures reinforced with geosynthetics can be seeded with grass or the layers can be filled with living plants during installation. Once the plants grow, the structure becomes a beautiful green home for insects and other animals from the local environment. Furthermore, geosynthetics allow builders to use natural elements in combination with reinforcement tools, providing better, more economical performance and beautiful results (Man et al. 2010). This is also the case for geosynthetic-reinforced soil slopes, as mentioned by Christopher (2014), which can be landscaped in accordance with the natural environment to provide an aesthetic advantage over retaining-wall structures. Lawson (2016) mentions that geotextile bags for revetments, which can be manufactured in appropriate colours, can blend in aesthetically with beach environments.

Another effort to showcase beauty in geosynthetics is the promotional video of the 7 th International Conference on Geosynthetics (Nice, France), which displays a fashion show where top models are clothed in geosynthetics (geotextiles, geogrids, geomembranes). Other similar initiatives came courtesy of manufacturers and were presented, for example, at the 10th International Conference on Geosynthetics in Berlin (see Figure 24). 


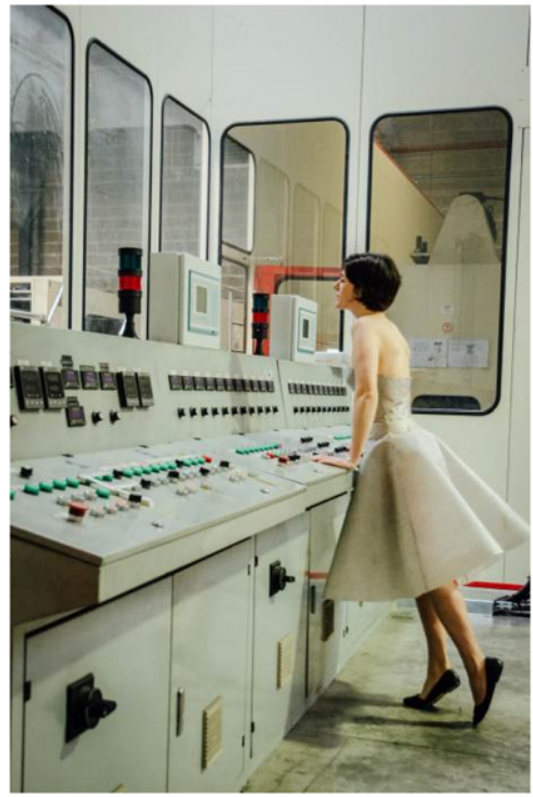

(a)

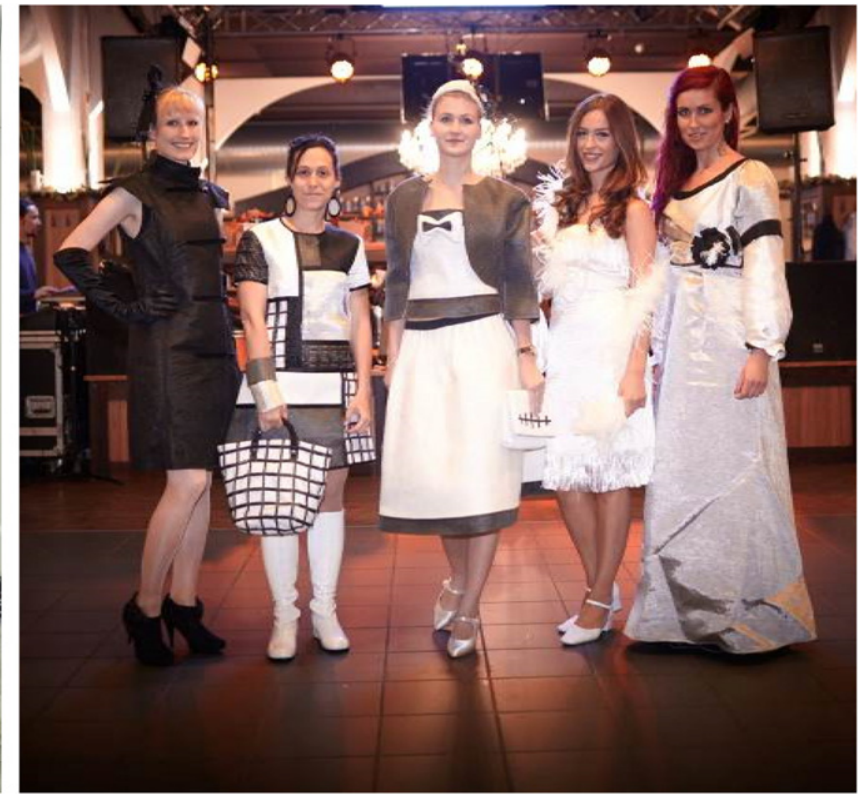

(b)

Figure 24. (a). M. Riot in a geotextile dress at the Afitex plant (courtesy M. Riot) and (b) presentation of a series of geosynthetics dresses during the 10 ICG in Berlin (courtesy G. Brau)

More recently, the IGS photo contest was conceived to ultimately compile an excellent collection of photos showcasing outstanding work by IGS members. One of the challenges in this lecture has been to illustrate the various sections with 'beautiful' pictures, and several photos from the IGS photo contests have been used for this purpose. Such contests have been extended to other countries or parts of the world, such as Brazil, North America, France and South Africa.

\subsubsection{Beautiful theories in geosynthetics}

Beauty in science is the physical beauty of the world, not only the visual beauty that is obvious to our eyes, but also the beauty inspired by the coherence and order of the world (Thuan 2013).

Unlike beauty in art, the beauty of a theory is not relative, it does not depend on times or cultures; it is universal. A beautiful theory must be simple in the hypotheses and axioms that support it, which is also a form of elegance. According to Thuan (2013), the last quality of a beautiful theory is that it makes beauty and truth coincide; it conforms to Nature.

In an effort to rework this definition, Jean-Pierre Giroud thought it best to first define the word 'theory' for a technical field. According to Giroud, a theory is an abstract description that aims to represent reality. In our field, abstraction is necessarily represented by mathematical equations and the accompanying text. Because the number of experiments we can conduct is limited, a theory has the power, through mathematics, to extrapolate what we learn from a limited number of experiments to an infinite number of cases. A theory thus not only explains observations but also predicts future events, making it essential for design purposes. This is the characteristic that makes a theory useful: it is the basis for accurate predictions. However, that alone does not make the theory beautiful.

Giroud also says that a beautiful theory must deal with an important topic and encompass various phenomena or be related to a complex mechanism. A beautiful theory must be elegant and thus simple, especially if it describes complex phenomena. The main characteristic of a beautiful theory may be its enlightening effect: it must clarify things for the user, allowing him or her to understand the phenomenon in question. Parameters must therefore be clearly identified, and their impact must be evaluated in a way that can be immediately understood. In addition, originality is also an important feature of a beautiful theory.

Finally, from among the theories he developed, Giroud suggests two theories from the field of geosynthetics that he finds beautiful: (i) the theory of how wrinkles develop in geomembranes and (ii) the filtration criteria, focusing on the retention criterion (the monumental theory on filtration juxtaposes various theories).

\subsubsection{Truth}

The notion of truth is diverse and refers to various orders: (1) knowledge, including scientific knowledge, (2) the ultimate truth, (3) stable reference points to guide one's life and (4) the alignment between reality and how we describe it. If the first two orders may be less consensual, the last two seem to be more universal. Alongside the concept of alignment between facts and speech, which is specific to Western civilisation, another complementary expression of truth has emerged in Asia, which is truth as consistency (Piorunski 1998; Lenoir 2012). In short, a proposition is true not only if it aligns with reality but also if it is consistent with other propositions that are part of the same paradigm. Through this approach, truth can be 
connected to a way of life, to human experience (both social and internal), and to our relationship with the world. The truth is what allows us to orient our life.

Thuan (2013) states that the goal of science is truth. Science approaches the truth in an asymptotic manner, including in the geosynthetics cosmos: the research done today is increasingly accurate and provides an increasingly precise description and analysis of specific phenomena, as most publications illustrate.

Truth is also a concern when it comes to respecting the rules of deontology and the veracity and originality of published data. The editors of the two official journals of the IGS, Geosynthetics International and Geotextiles and Geomembranes, have made tremendous continuous efforts over the past decades to ensure quality publications through a peer-review process. Similar review processes are also in place for organising regional or international conferences. Such criteria are necessary and must be maintained to continue to ensure the credibility of the information produced in the field of geosynthetics. According to the code of ethics of the IGS, no member of the IGS will knowingly issue a false statement or false information.

\subsubsection{Justice}

Justice aims to establish laws, equality between humans, peace, and a sharing of land and of wealth (Lenoir 2012). Although justice appears among the most constant and entrenched values in all cultures of the world, the challenge is to make it come alive in our actions. Svâmi Prajnânpad, an Indian sage, says that justice is a law of exchange, which is why it is so difficult. The one who gives before taking or is ready to give as soon as he takes, who considers all others like him from the depths of himself and considers no one as being foreign to him, is on the path of justice (Comte-Sponville 1997).

SDG 16 of the United Nations emphasises justice, which is one of the three values along with freedom and respect to appear in the 17 goals. SDG 16 states that national and local institutions must be accountable and deliver equitably to all without requiring bribes. No planetary civilisation can be sustainable without justice being implemented at all levels of social life (Lenoir 2012).

Giroud (2006) states that no existing research society would have treated as equals polymer scientists and geotechnical engineers, textile or plastic manufacturers and earthwork contractors, civil engineering design firms and material suppliers. No existing society would have provided an open forum for civil engineers and the synthetics industry, as does the IGS. Justice is thus provided to members in the IGS, and the pursuit of justice is what allowed the IGS to obtain an international consensus.

During election periods, IGS presidents never fail to encourage recommendations of people to the various seats to try and ensure good representation from all parts of the world in the IGS council. In addition, election by direct voting of IGS members has historically led to a good balance of constituencies in the IGS Council, both geographically and professionally (Zornberg 2012).
Each IGS chapter has access to a dedicated web page on the IGS website, can contribute to each issue of the IGS news and can compete for the selection of nominees for awards or to organise a regional or international conference.

The IGS also contributes to improving environmental justice. According to the Lancet Commission on Pollution and Health (The Lancet Commission 2017), pollution and pollution-related disease are often reflections of environmental injustice, which is the inequitable exposure of poor, minority and disenfranchised populations to toxic chemicals, contaminated air and water, unsafe workplaces and other forms of pollution. The concomitant disproportionate affliction of these populations by pollution-related disease amounts to a violation of their human rights. A core principle of environmental justice is that all people and communities are entitled to equal protection by environmental and public health laws and regulations.

International development organisations, including UN agencies, multilateral development banks, bilateral funding agencies, private foundations, and nongovernmental organisations, have important responsibilities regarding pollution control and the prevention of pollution-related disease that complements and extends the role of governments. These agencies should elevate pollution prevention in the agenda of international development and global health and substantially increase the resources they devote to fighting pollution (Lancet Commission on Pollution and Health (The Lancet Commission 2017)). In this instance, a better sharing of the resources produced by the IGS would undoubtedly help increase environmental justice around the world. This is the option selected by the French chapter of the IGS, which gives free access to their web site and state-of-the-art references on the use of geosynthetics (in French and English). And free should not be considered synonymous to worthless when it brings more justice.

The geosynthetics community is searching for ways to educate engineering students about geosynthetics and to increase their awareness of the usefulness of geosynthetics. Dixon et al. (2017) mention the IGS sustainability movie as a good example of IGS educational material. This movie, together with the IGS leaflets, has been translated into various languages, facilitating their appropriation. Short courses and training lectures are also available at international conferences.

One IGS initiative that has encountered success is the EtE program. The main goal of this program is to ensure that every student graduating from an undergraduate engineering program receives some basic exposure to geosynthetics. One way to implement this action is to supply educators with the necessary knowledge and tools to help them integrate geosynthetic topics into their engineering curricula. EtE events provide attending professors with a host of resources to support this mission. Such events have already been organised in Argentina, Portugal, Poland, the USA, the Philippines (see Figure 25), Indonesia, China and Brazil. The IGS 


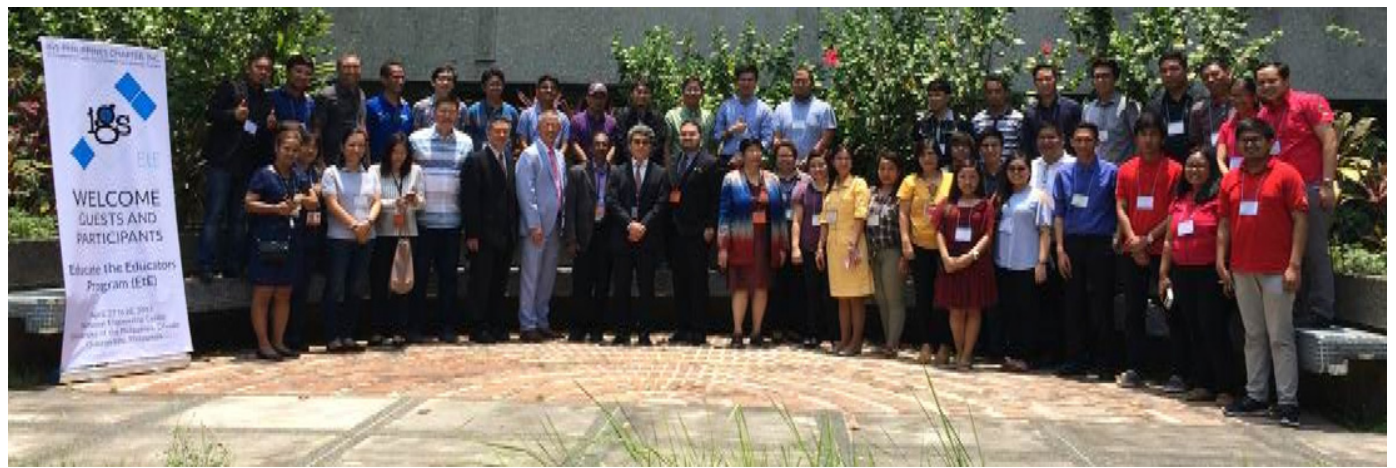

Figure 25. The EtE group in Manila, the Philippines, April 2017 (courtesy B. Ramsey)

provides equal support to all chapters for organising an EtE event.

\subsubsection{Respect}

Lenoir (2012) says that at the heart of respect for the other is the recognition that the other, whether an individual or a group, must have a space where dreams and aspirations can be expressed. Respect is the recognition that each individual has the right to make their own choices in life, and that they are to be respected in their choices for who they are.

This value is expressed through the golden rule, which I express here according to Confucius: 'What you do not want done to yourself, do not do to others'. The golden rule appears under different guises in Hinduism, Buddhism, Jaïnism, Zoroastrism, Judaism, Christianism and Islam.

In his address to members, Tatsuoka (2006) argued for more and better local activities and communications in local languages through local organisations and local collaborations in addition to the international IGS activities. Chapters are thus encouraged to develop along paths that they define themselves, with the goal being that their development becomes tailored to local conditions. Chapters thus have the possibility, following minimal guidelines given by the IGS, to develop themselves and to organise at their convenience events that are meaningful in their country.

As previously mentioned, the IGS is a society in which coexist groups as diverse as polymer scientists and geotechnical engineers, textile or plastic manufacturers and earthwork contractors and civil engineering design firms and material suppliers. This coexistence is possible because respect is offered and each individual or company has the possibility to develop following his, her, or its own focus of development. Respect is all the more important when different research teams work on similar topics from different approaches that can benefit from each other, and when different manufacturers coexist and produce geosynthetics from the same family of products (geotextiles, geomembranes, geogrids, GCLs, etc.).

Respect is the basis to ensure this coexistence and the development of the IGS. Following the code of ethics of the IGS, no member of the IGS will make any abusive, racist, sexist, homophobic, ageist, discriminatory or otherwise inappropriate comments or derogatory or stereotypical remarks about a particular ethnic, political, social or religious group or gender.

\subsubsection{Love}

At the most collective level, a form of love exists that can be found to various degrees in all cultures; namely, compassion. Compassion may be defined as an expression of love toward people that are in a state of suffering, misfortune, injustice, and thus in a situation of weakness (Lenoir 2012). Compassion is what we express when one of the IGS chapters loses a member. We collectively share the pain with the local chapters, the friends, and the family.

We also express compassion when one of our local chapters faces a natural disaster. Unfortunately, numerous such disasters occur each year, and the local people receive messages of support from our community from all around the world. Certainly, one such event that has greatly impacted us is the great Tohoku earthquake and tsunami which has given rise, beyond the expressions of sympathy, to the organisation of dedicated sessions in conferences all around the world, which can be interpreted as a proof of compassion from the organisers. The ultimate resource is people - especially skilled, spirited, and hopeful young people endowed with liberty - who can exert their will and imagination for their own benefit and for the benefit of the rest of us as well (Simon 1995).

The IGS council, under the impulse of its president Jorge Zornberg, approved in December 2012 the creation of the IGS Young Members Committee (Zornberg 2013). The idea of creating this committee arose after the 2009-2012 IGS student awardees showed interest in becoming more involved in the IGS. Consequently, the founding members of this Young Members Committee are the IGS student awardees for the years 2009-2012. The IGS has dedicated time, energy, and money to support the creation and development of this committee in what I consider a proof of love toward these young members who have now entered freely into action (see Figure 26).

\subsubsection{Freedom}

The theme of freedom in the modern Western world has evolved into the autonomy of individuals, emancipation 


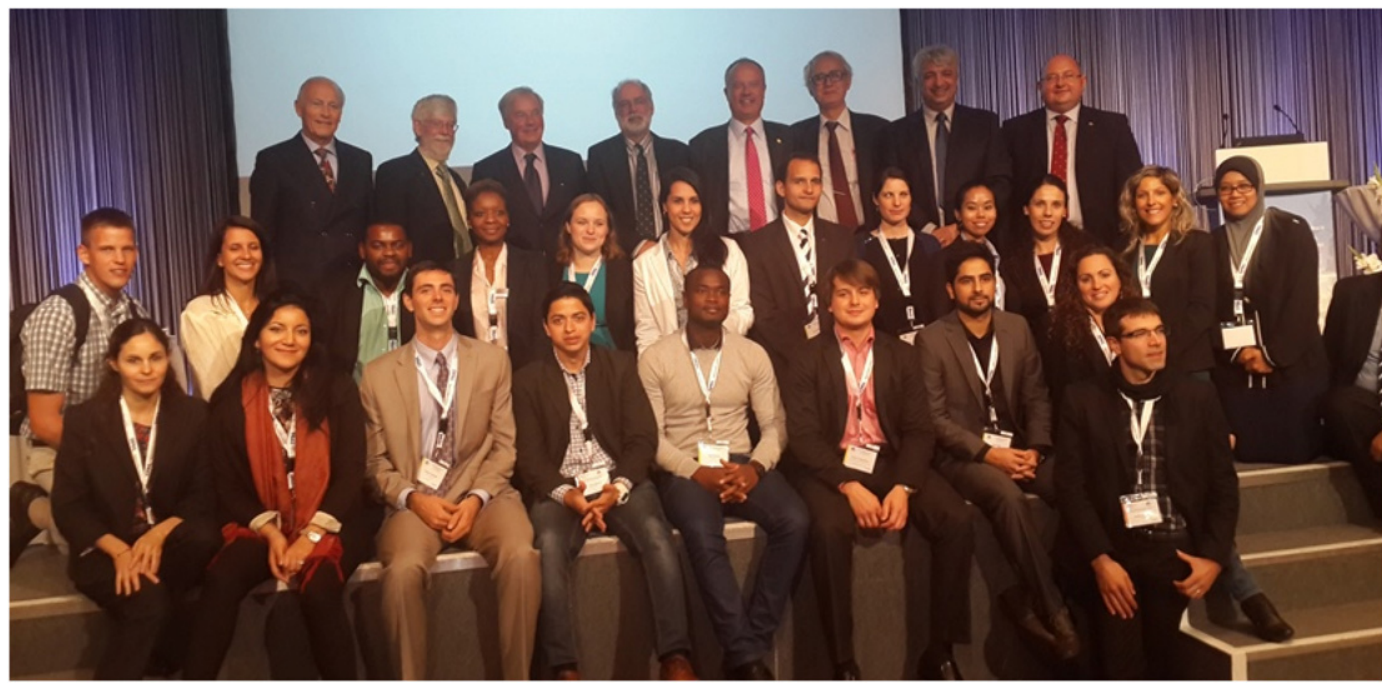

Figure 26. The young members and president and past presidents of the IGS during the 10 ICG in Berlin (IGS news, 2014)

from the group, and rejection of the arbitrary (Lenoir 2012). It is on this basis that the United Nations emphasises the right to freedom of information and to express one's views in private and in public. People should have the freedom to contribute to decisions that affect their lives. Fundamental freedoms should be protected, in accordance with national legislation and international agreements.

The concept of freedom is complementary to the concept of availability that developed in Asia. If freedom involves a choice, availability is equivalent to dissolving all position, not taking sides, being entirely 'open' and making no a priori projection, which allows us to miss nothing (Aeschiman 2015).

In the IGS, each member is free to express his or her views and to act and behave as they see fit, provided the IGS code of ethics is followed. This is demonstrated by the approach of the IGS to organising regional or international conferences: the IGS provides a helpful checklist, although the local organisers have significant flexibility. A clear example of this culture occurred during the debate about whether to organise the Eurogeo 6 conference in Istanbul, which involved security concerns, or move it to Slovenia. The organiser, Erol Güler, obtained a decision from a show of hands, with the full support of the IGS council. The technical committees created by the IGS on soil reinforcement, barrier systems, filtration, hydraulics, and stabilisation, also benefit from the freedom to do their own work and to plan meetings at their convenience.

Young scientists need thorough training in their field, but they should also be encouraged to look beyond the boundaries of their field and work in partnership with others to address real-world challenges. Too often, the incentive structure of promotions and job security drives the upcoming generations of investigators to turn inward to address academic questions restricted to their disciplines instead of turning outward to seek partnerships and address societal challenges (Myers 2017). The freedom allowed the IGS Young Members has made them an exception to this trend. They took full advantage of their freedom and now fully contribute to the IGS council meeting in numerous ways. They organise themselves, as evidenced by their report in the IGS news, and they initiate events, workshops and interactions with senior members. A particularly poignant example of their organisation is the Young IGS Members paper contest along the 11th International Conference on Geosynthetics in Seoul. The Young IGS Members also held their first-ever photo contest in 2018 and a logo context in 2019. I see very few limits to the initiative of these young members given the freedom they enjoy.

\section{CONCLUSION}

This Giroud Lecture has presented a systemic view of what geosynthetics can contribute to resolving the many facets of the current global crisis: to provide quality water to all, feed the world, protect the environment, mitigate natural disasters, provide economic solutions, and connect people to help them live together.

After a first section that presents the various aspects of the global crisis and their interconnections, several fields are discussed. Not all possible uses of geosynthetics are covered or discussed in excessive detail; the intention is rather to show in which fields geosynthetics are at work.

The interactions between aspects of the global crisis require a global resolution that involves working together on the various aspects of the crisis to reach a sustainable solution. Climate change and the aggravation of aspects of the crisis that results from climate change received particular attention.

The issue of water quality was addressed next. The main structures that contribute to the capture, transportation, storage, and distribution of freshwater were presented and discussed in terms of the functions fulfilled by geosynthetics structures. Ways to preserve water quality and to increase geomembrane lifetime in hydraulic applications were particularly emphasised. 
Geosynthetics can also contribute to feeding the world through erosion control, crop protection and enhancement and fish farming. Agricultural waste must also be managed in an environmentally friendly way, and geosynthetics play an important role in this area.

The use of geosynthetics to control pollution from landfills and mining sites was also discussed. Geosynthetics can contribute to treating sludge and sediments and can enhance the production of renewable energy from waste or at waste-treatment sites. These factors demonstrate another contribution of geosynthetics to the mitigation of climate change.

Another topic discussed was water management. Although necessary for life, water can also threaten life and infrastructure, and this threat is aggravated by climate change. Geosynthetics can help mitigate this threat by protecting against coastal erosion, floods and landslides and by reinforcing soil and soil walls and stabilising slopes.

As an added benefit, the use of geosynthetics in all these aforementioned applications is shown to yield financial benefits.

To take full advantage of the benefits offered by geosynthetics, people must live together, which can only occur if people are connected. Roads, railroads and bridges play a large part in this, and the lecture discusses how geosynthetics can help in all of these sectors.

Finally, the Giroud lecture closes with a discussion of human values and how they are implemented in the IGS. When these values are combined with the technical, environmental and economic contributions of the IGS, we can help to build a new sustainable global society.

The IGS is thus a fully developed society with all the necessary skills and knowledge, not only in technical domains but also through lifestyle choices made within its fold, to make significant contributions to healing our world.

\section{ACKNOWLEDGEMENTS}

My first acknowledgements go to J. P. Giroud and the IGS council, who gave me the opportunity to deliver this Giroud lecture. I would also like to address special thanks to J. P. Giroud, N. Dixon, B. Ramsey and D. Shercliff, who thoroughly reviewed this lecture. Thanks also go to B. Kraabel, from Physical Sciences Communication, who significantly helped me to improve the quality of my English. I also thank all those who contributed by supplying me with the numerous references that were used in this lecture: O. Artières, B. Amat, R. J. Bathurst, D. Cazzuffi, N. Dixon, I. Fraser, J. P. Giroud, J. Han, T. Katsumi, R. Koerner, C. Lawson, B. Ramsey, M. R. Santafe, R.K. Rowe, S. Shukla, F. Tatsuoka, C. W. Hsieh, C. Yoo and J. Zornberg. Thanks also to those who contributed to my intent to inject some beauty into this lecture: F. Peyriguer for the elaboration of Figures 1-4 and O. Artières, A.L. Backes, M. Blanco, G. Braü, P. Brochier, S. Calendine, L. Carbone, D. Cazzuffi, J. P. Giroud, R. Holm, T. Katsumi, R. Koerner,
F. Moinereau, T. A. Paulo, E. Peggs, D. Poulain, B. Ramsey, M. R. Santafe, F. Tatsuoka, K. von Maubeuge and E. Zannoni. Finally, I would like to acknowledge the contribution of B. Escande and J. Pagès. Without their initiative to include other fields this Giroud lecture would have been completely different.

\section{REFERENCES}

Aeschimann, E. (2015). Comment dit-on liberté à Pékin? Les 7 notions clés de la pensée chinoise. See https://bibliobs.nouvelobs.com/essais/ 20150319.OBS5039/comment-dit-on-liberte-a-pekin-les-7-notionscles-de-la-pensee-chinoise.html.

AFNOR (n.d.). EN ISO 10318: Geosynthetics - Terms and definitions. AFNOR, Paris, France.

Alexander, T. (2010). Solar energy landfill caps. Waste Advantage Magazine, June, 28-32.

Allen, E. W. (2008). Process water treatment in Canada's oil sands industry: I. Target pollutants and treatment objectives. Journal of Environmental Engineering and Science, 7, No. 2, 123-138.

Allen, S. \& Sprague, C. J. (2011). Carbon footprint implications of the erosion control response. Proceedings 24th Annual GRI Conference: Optimizing Sustainability Using Geosynthetics, Dallas, TX, USA. The Geosynthetic Institute, Philadelphia, PA, USA, pp. 86-93.

Allen, T. M., Bathurst, R. J. \& Berg, R. R. (2002). Global level of safety and performance of geosynthetic walls: an historical perspective. Geosynthetics International, 9, No. 5-6, 395-450.

Barrington, S. F., El Moueddeb, K., Jazestani, J. \& Dussault, M. (1998). The clogging of nonwoven geotextiles with cattle manure slurries, Geosynthetics International, 5, No. 3, 309-325.

Bathurst, R. (2014). Challenges and recent progress in the analysis, design and modelling of geosynthetic reinforced soil walls, the 5th Giroud lecture. 10th International Conference on Geosynthetics, 10 $I C G$, Berlin, Germany, Ziegler, M., Braü, G., Heerten, G. and Laackmann, K. Editor, Deutsche Gesellschaft Fuer Geotechnik (DGGT), Essen, Germany, pp. 180-218.

Beauregard, M. S., Krunanithi, A. T. \& Clevenger, C. M. (2016). Comparative life cycle assessment of two design alternatives for a geosynthetic reinforced bridge abutment. 3rd Pan American Conference on Geosynthetics, Geoamericas 2016, Miami, FL, USA, pp. 1786-1797.

Benedetti, P. F., Fayoux, D., Verbrugghe, S. \& Potié, G. (2009). Stockage d'eau potable de grande capacité par couverture flottante et géomembrane en PVC - L'expérience corse. Rencontres Géosynthétiques 2009, Nantes, France, Comité Français des Géosynthétiques, Rueil-Malmaison, France, 10pp (in French).

Blanchet, J. F. (2017). Les besoins en eau vont augmenter de 14 à $16 \%$ d'ici 2050. AgraFil, Jeudi 18 au Mercredi 24 mai, 4pp (in French).

Blanco, M., Castillo, F., Garcia, F., Soriano, J., Noval, A., Touze-Foltz, N., Pargada, L., Rico, G. \& Aguiar, E. (2012a). Comparative study of three different kinds of geomembranes (PVC-P, HDPE, EPDM) used in the waterproofing of reservoirs. Proceedings Eurogeo 5, Valencia, Spain, Blanco, M., Leiro, A., Mateo, B., Torregrosa, J. B., Abad, F., Pardo de Santayama, F. and Santalla, J., Editors, vol. 2, pp. 46-54.

Blanco, M., Leiro, A., Soriano, J., Crespo, M., Zornberg, J. \& Aguiar, E. (2012b). Long-term performance of the 'Laguna de Barlovento' reservoir waterproofing using a PVC-P geomembrane. Proceedings Eurogeo 5, Valencia, Spain, Blanco, M., Leiro, A., Mateo, B., Torregrosa, J. B., Abad, F., Pardo de Santayama, F. and Santalla, J., Editors, vol. 2, pp. 55-63.

Blanco, M., Mateo, B., Cazzuffi, D. \& Crespo, M. (2017). Lining of reservoirs with synthetic membranes. Proceedings Geoafrica 2017, Marrakech, Morocco, pp. 113-153.

Blanco, M., Touze-Foltz, N., Pérez Sánchez, M., Redon-Santafe, M., Sánchez Romero, F. J., Torregrosa Soler, J. B. \& Zapata Raboso, F. A. (2018). Durability of reinforced PVC-P geomembranes installed in reservoirs in eastern Spain. Geosynthetics International, 25, No. 1, 85-97. 
Bouazza, A. (2013). Geosynthetics in mining applications. Proceedings Geoafrica 2013, Accra, Ghana, 34p.

Bouazza, A. \& Heerten, G. (2012). Geosynthetic applications sustainability aspects. In Handbook of Geosynthetic Engineering, Second Edition, Shukla, S. K., Editor, ICE, London, UK, pp. 387-396.

Bourdeau, P. L. \& Ashwamy, A. K. (2012). Unpaved roads. In Handbook of Geosynthetic Engineering, Second Edition, Shukla, S. K., Editor, ICE, London, UK, pp. 163-177.

Boutron, O., Gouy, V., Touze-Foltz, N., Benoit, P., Chovelon, J. M. \& Margoum, C. (2009). Geotextile fibres retention properties to prevent surface water nonpoint contamination by pesticides in agricultural areas. Geotextiles and Geomembranes, 27, No. 4, 254-261.

Brachman, R. W. I. \& Sabir, A. (2013). Long-term assessment of a layered-geotextile protection layer for geomembranes. Journal of Geotechnical and Geoenvironmental Engineering, 139, No. 5, 752-764.

Brandl, H. (2010). Geosynthetics application for the mitigation of natural disasters. The 4th Giroud lecture. Proceedings 9th International Conference on Geosynthetics, Guaruja, Brazil. Brazilian Chapter of the International Geosynthetics Society (IGSBrazil), São Paulo, Brazil, pp. 67-112.

Brandl, H. (2011). Geosynthetics applications for the mitigation of natural disasters and for environmental protection. Geosynthetics International, 18, No. 6, 340-390.

Brooks, A. E., Allen, N., Lonij, V. P. \& Cronin, A. D. (2011). Evaluation of four geomembrane-mounted PV systems for land reclamation in Southern Arizona. Proceedings 38th Photovoltaic Specialists Conference, pp. 520-525.

Cazzuffi, D., Giroud, J. P., Scuero, A. \& Vaschetti, G. (2010). Geosynthetics barriers systems for dams. Proceedings 9th International Conference on Geosynthetics, Guaruja, Brazil. Brazilian Chapter of the International Geosynthetics Society (IGSBrazil), São Paulo, Brazil, pp. 115-163.

Cazzuffi, D., Scuero, A. \& Vaschetti, G. (2012). Hydraulic tunnels. In Handbook of Geosynthetic Engineering, second edition (Shukla, S. K., Editor). Institution of Civil Engineers, London, UK, pp. 303-315.

Christopher, B. (2014). Cost savings by using geosynthetics in the construction of civil work projects. 10th International Conference on Geosynthetics, 10 ICG, Berlin, Germany, Ziegler, M., Braü, G., Heerten, G. and Laackmann, K., Editors, Deutsche Gesellschaft Fuer Geotechnik (DGGT), Essen, Germany, 19pp (in French).

Comte-Sponville, A. (1997). De l'autre côté du désespoir. Introduction à la pensée de Svâmi Prajnanpâd. Accarias/L’Originel, Paris, France (in French).

Compte-Sponville, A. (2006). L'esprit de l'athéisme, introduction à une spiritualité sans Dieu. Albin Michel Ed., 228 p.

Craggs, R., Park, J., Sutherland, D. \& Heubeck, S. (2015). Economic construction and operation of hectare-scale wastewater treatment enhanced pond systems. Journal of Applied Phycology, 27, No. 5, 1913-1922.

Cuomo, S., Moretti, S., D’Amico, A., Frigo, L. \& Aversa, S. (2020). Modelling of geosynthetic-reinforced barriers under dynamic impact of debris avalanche. Geosynthetics International, 27, No. 1, 65-78.

Damians, I. P., Bathurst, R. J., Adroguer, E., Josa, A. \& Lloret, A. (2017). Environmental assessment of earth retaining wall structures. ICE Environmental Geotechnics, 4, No. 6, 415-431.

Damians, I. P., Bathurst, R. J., Adroguer, E., Josa, A. \& Lloret, A. (2018). Sustainability assessment of earth retaining wall structures. ICE Environmental Geotechnics, 5, No. 4, 187-203.

DeGarie, C. J., Crapper, T., Howe, B. M., Burke, B. F. \& Mc Carthy, P. J. (2000). Floating geomembrane covers for odour control and biogas collection and utilization in municipal lagoons. Water Science and Technology, 42, No. 10-11, 291-298.

Dixon, N., Raja, J., Fowmes, G. \& Frost, M. (2016). Sustainability aspects of using geotextiles. In Geotexiles From Design to Applications, Koerner, R. M., Editor, Elsevier, Amsterdam, The Netherlands.
Dixon, N., Fowmes, G. \& Frost, M. (2017). Global challenges, geosynthetic solutions and counting carbon. Geosynthetics International, 24, No. 5, 451-464.

Ehrenberg, H., Mermet, J. P., Stucki, M., Büsser, S., Itten, R., Frischknecht, R. \& Wallbaum, H. (2012). Comparative life cycle assessment of geosynthetics versus conventional construction materials, a study on behalf of the E.A.G.M. General. Proceedings Eurogeo 5, Valencia, Spain, Blanco, M., Leiro, A., Mateo, B., Torregrosa, J. B., Abad, F., Pardo de Santayama, F. and Santalla, J., Editors, vol. 4, pp. 87-91.

Elsing, A., Fraser, I., Stucki, M., Büsser, S., Itten, R., Frischknecht, R. \& Wallbaum, H. (2012). Comparative life cycle assessment of geosynthetics versus conventional construction materials, a study on behalf of the E.A.G.M., Case 2, foundation stabilization. Proceedings Eurogeo 5, Valencia, Spain, Blanco, M., Leiro, A., Mateo, B., Torregrosa, J. B., Abad, F., Pardo de Santayama, F. and Santalla, J., Editors, vol. 1, pp. 60-64.

Farcas, F., Fayolle, B., Richaud, E. \& Azzouz, M. (2012). Phenolic stabilisers extraction constants of polypropylene geotextiles determination in alkali medium. Proceedings Eurogeo 5, Valencia, Spain, Blanco, M., Leiro, A., Mateo, B., Torregrosa, J. B., Abad, F., Pardo de Santayama, F. and Santalla, J., Editors, 5pp.

Farkish, A. \& Fall, M. (2013). Rapid dewatering of oil sand mature fine tailings using super absorbent polymer (SAP). Minerals Engineering, 50-51, 38-47.

Faure, Y. H. \& Meydiot, V. (2002). Secondary function of a complete drainage system: waterproofing. Proceedings 7 th International Conference on Geosynthetics, Nice, France, Delmas, Ph. and Gourc, J. P., Editors. Balkema, Rottermadam, The Netherlands, pp. 549-552. ISBN 9058095258.

Faure, Y. H., Matichard, Y., Brochier, P. \& Suryolelono, K. (1993). Experimental and theoretical methodology to validate new geocomposite structures for drainage. Geotextiles and Geomembranes, 12, No. 5, 397-412.

Ferrer-Gisbert, C., Ferrán-Gozálvez, J. J., Redón-Santafé, M., Ferrer-Gisbert, P., Sánchez-Romero, F. J. \& Torregrosa-Soler, J. B. (2013). A new photovoltaic floating cover system for water reservoirs. Renewable Energy, 60, 63-70.

Forzieri, G., Cescatti, A., Batista e Silva, F. \& Feyen, L. (2017). Increasing risk over time of weather-related hazards to the European population: a data-driven prognostic study. Lancet Planetary Health, 1, No. 5, e200-e208.

Fourie, A. B. \& Jones, C. J. F. P. (2010). Improved estimates of power consumption during dewatering of mine tailings using electrokinetic geosynthetics (EKGs). Geotextiles and Geomembranes, 28, No. 2, 181-190.

Fourmont, S. \& Arab, R. (2005). Cover landfill drainage systems. Drainage and waterproofing for semi-permeable landfill capping. Proceedings International Workshop Hydro-Physico-Mechanics of Landfills, Grenoble, France, Gourc, J. P., Editor, 4pp.

Fourmont, S., Castanet, E., Desbonnets, R. \& Faivre, J. M. (2009a). Drainage et imperméabilisation de la couverture du CSD de Saint Bres. Rencontres Géosynthétiques 2009, Nantes, France, pp. 461-465 (in French).

Fourmont, S., Malaret, O. \& Chalot, L. (2009b). Réalisation de la couverture de la décharge de la Trompeuse (Martinique). Rencontres Géosynthétiques 2009, Nantes, France, pp. 455-460 (in French).

Fraser, I., Elsing, A., Stucki, M., Büsser, S., Itten, R., Frischknecht, R. \& Wallbaum, H. (2012). Comparative life cycle assessment of geosynthetics versus conventional construction materials, a study on behalf of the E.A.G.M., Case 4, soil retaining wall. Proceedings Eurogeo 5, Valencia, Spain, Blanco, M., Leiro, A., Mateo, B., Torregrosa, J. B., Abad, F., Pardo de Santayama, F. and Santalla, J., Editors, vol. 5, pp. 218-222.

Gastaud, S., Stoltz, G., Dolez, P., Blond, E. \& Touze-Foltz, N. (2015). Laboratory device to characterize electrokinetic geocomposites for fluid fine tailings dewatering. Canadian Geotechnical Journal, 52, No. 4, 505-514.

Gastaud, S., Dolez, P., Blond, E. \& Touze-Foltz, N. (2017). Dewatering of oil sands tailings with an electric geocomposite. Minerals Engineering, 100, 177-186. 
Giroud, J. P. (2005). Quantification of geosynthetic behaviour. Geosynthetics International, 12, No. 1, 2-26.

Giroud, J. P. (2006). A short history of the origins of the IGS. Proceedings 8th International Conference on Geosynthetics, Yokohama, Japan, Kuwano, J. and Koseki, J., Editors. Millpress, Rotterdam, The Netherlands, pp. 3-6.

Giroud, J. P. \& Plusquellec, H. (2017). Water, canals and geosynthetics. Keynote Lecture, Proceedings Geoafrica 2017, Marrakech, Morocco, pp. 53-112.

Glendinning, S., Jones, C. J. F. P., Huntley, D. T. \& Lamont-Black, J. (2006). Dewatering of sewage sludge using electrokinetic geosynthetics. Proceedings 8 th International Conference on Geosynthetics, Yokohama, Japan, Kuwano, J. and Koseki, J., Editors. Millpress, Rotterdam, The Netherlands, pp. 527-530.

Han, J. \& Guo, J. (2017). Geosynthetics used to stabilize vegetated surfaces for environmental sustainability in civil engineering Frontiers of Structural and Civil Engineering, 11, No. 1, 56-65.

Heerten, G. (2012). Reduction of climate-damaging gases in geotechnical engineering practice using Geosynthetics. Geotextiles and Geomembranes, 30, 43-49.

Heibaum, M. (2010). Geosynthetics in agricultural and aquacultural applications. Proceedings 9th International Conference on Geosynthetics, Guaruja, Brazil. Brazilian Chapter of the International Geosynthetics Society (IGSBrazil), São Paulo, Brazil, pp. 259-271.

Heibaum, M. (2014). Natural disasters mitigation by using construction methods with geosynthetics (flooding). Proceedings 10th International Conference on Geosynthetics, 10 ICG, Berlin, Germany, Ziegler, M., Braü, G., Heerten, G. and Laackmann, K., Editors, Deutsche Gesellschaft Fuer Geotechnik (DGGT), Essen, Germany, 16p.

Heibaum, M., Fourie, A., Girard, H., Karunaratne, G. P., Lafleur, J. \& Palmeira, E. M. (2006). Hydraulic applications of geosynthetics. Proceedings 7 th International Conference on Geosynthetics, Yokohama, Japan, Kuwano, J. and Koseki, J., Editors. Millpress, Rotterdam, The Netherlands, pp. 79-120.

Hsieh, C. W. (2008). Using geosynthetics for fishery applications in Taiwan. Proceedings of the GRI-21 Conference on Agriculture and Aquaculture, Cancun, Mexico, pp. 84-93.

Hsieh, C. W. (2016). Geotextiles in agriculture and aquaculture. In Geotextiles, From Design to Applications, Koerner, R. M., Editor, Elsevier, Amsterdam, The Netherlands, pp. 511-530.

Hsuan, G., Schroeder, H. F., Rowe, R. K., Müller, W., Greenwood, J., Cazzuffi, D. \& Koerner, R. M. (2008). Long-term performance and lifetime prediction of geosynthetics. Keynote lecture. Proceedings Eurogeo 4, Edinburgh, UK, Dixon, N. Editor, 40p.

IGS (International Geosynthetics Society) (n.d.a). Geosynthetics in Hydraulic Projects. IGS, Austin, TX, USA.

IGS (n.d.b). Geosynthetics in Agricultural Applications. IGS, Austin, TX, USA.

IGS (n.d.c). Geosynthetics in Road Engineering. IGS, Austin, TX, USA.

IGS (n.d.d). Geosynthetics in Railroads. IGS, Austin, TX, USA.

Inui, T., Yasutaka, T., Endo, K. \& Katsumi, T. (2012). Geo-environmental issues induced by the 2011 off the Pacific coast of Tohoku earthquake and tsunami. Soils and Foundations, 52, No. 5, 856-871.

IPPC (2014). Climate change 2014: synthesis report. Contribution of Working Groups I, II and III to the Fifth Assessment Report of the Intergovernmental Panel on Climate Change. (Core writing team: Pachauri, R. K. and Meyer, L. A. Editors). IPPC, Geneva, Switzerland, $167 \mathrm{pp}$

Jeeravipoolvarn, S., Scott, J. D. \& Chalaturnyk, R. J. (2009). $10 \mathrm{~m}$ standpipe tests on oil sands: long term experimental results and prediction. Canadian Geotechnical Journal, 46, No. 8, $875-888$.

Jones, D. R. V. (2015). Using geosynthetics for sustainable development. The 2nd International GSI-Asia Geosynthetics Conference (GSI-Asia 2015), Seoul, Korea, Jeon, H. Y., Editor, The Geosynthetics Institute, Seoul, Korea, 4pp.

Jones, R. V. \& Dixon, N. (2011). European perspectives on sustainable development using geosynthetics. Proceedings 24th Annual GRI
Conference: Optimizing Sustainability Using Geosynthetics, Dallas, TX, USA, The Geosynthetic Institute, Philadelphia, PA, USA, pp. 1-7.

Jones, C., Lamont-Black, J., Glendinning, S., Bergado, D., Eng, T., Fourie, A., Liming, H., Pugh, C., Romantshuk, M., Simpanen, S. \& Yan-Feng, Z. (2008). Recent research and applications in the use of electro kinetics geosynthetics. Proceedings Eurogeo 4, 4th European Geosynthetics Conference, Edinburgh, UK, Dixon, N., Editor, pp. $1-30$.

Jones, C. J. F. P., Lamont-Black, J. \& Glendinning, S. (2014). The environmental sustainability of electrokinetic geosynthetic strengthened slopes. Engineering Sustainability, 167, No. ES3, 95-107

Kant, E. (2015). Critique de la faculté de juger, Flammarion, Paris, France (in French)

Koerner, R. M., Hsuan, Y. G. \& Koerner, G. R. (2008). Freshwater and geosynthetics: a perfect marriage. The First Pan American Geosynthetics Conference and Exhibition, Geoamericas, pp. 4-28.

Koerner, R. M., Hsuan, Y. G. \& Koerner, G. R. (2017). Lifetime predictions of exposed geotextiles and geomembranes. Geosynthetics International, 24, No. 2, 198-212.

Laidié, N., Shercliff, D., Stucki, M., Büsser, S., Itten, R., Frischknecht, R. \& Wallbaum, H. (2012). Comparative life cycle assessment of geosynthetics versus conventional construction materials, a study on behalf of the E.A.G.M., case 1, filter function. Proceedings Eurogeo 5, Valencia, Spain, Blanco, M., Leiro, A., Mateo, B., Torregrosa, J. B., Abad, F., Pardo de Santayama, F. and Santalla, J., Editors, vol. 2, pp. 153-157.

Land and Water (2007). Anaerobic digester provides ideal application for EPDM geomembrane. Land and Water, November/December 2007, 3pp.

Lawson, C. R. (2006). Geotextile containment for hydraulic and environmental engineering. Proceedings 8th International Conference on Geosynthetics, Yokohama, Japan, Kuwano, J. and Koseki, J., Editors, Millpress, Rotterdam, The Netherlands, pp. $9-48$.

Lawson, C. R. (2008). Geotextile containment for hydraulic and environmental engineering. Geosynthetics International, 15, No. 6 , $384-427$.

Lawson, C. R. (2014). Dewatering and beneficial reuse of dredged contaminated sediments using geotextile tubes. Proceedings 7th International Conference on Environmental Geotechnics, Melbourne, Australia, Bouazza, M., Yuen, S. and Brown, B., Editors. Engineers Australia, Canberra, Australia, pp. 111-135.

Lawson, C. R. (2016). Geotextiles in marine engineering. In Geotextiles, From Design to Applications, Koerner R. M., Editor, Elsevier, Amsterdam, The Netherlands, pp. 435-482.

Lenoir, F. (2012). La guérison du monde. Fayard (in French).

Levita, V. (2017). Le réveil économique passera par les infrastructures. Les Echos, No. 22514, 7 (in French).

L'Humanité (2017). La lutte contre le réchauffement est un facteur de paix évident. Interview de Valéry Laramée de Tanneberg, 4th Dec. 2017, 809 words (in French).

Man, T. E., Blenesi-Dima, A. \& Constantinescu, L. (2010). Technical solution to create esthetical civil engineering structures using the geosynthetics materials. Annals, Food Science and Technology, 11, No. 1, 111-117.

Meydiot, V. \& Lambert, S. (2000). Influence of joins on transmissivity of drainage geocomposites. Proceedings Eurogeo 2, Cancelli, A., Cazzuffi, D. and Soccodato, C., Editors, vol. 2, pp. 773-777.

Mikula, R. J., Kasperski, K. L., Burns, R. D. \& MacKinnon, M. D. (1996). Nature and fate of oil sands fine tailings, suspensions: fundamentals and applications in the petroleum industry. American Chemical Society, 251, 677-723.

Mohri, Y., Matsushima, K., Yamazaki, S., Lohani, T. N., Tatsuoka, F. \& Tanaka, T. (2009). New direction for earth reinforcement: disaster prevention for earthfill dams. Geosynthetics International, 16, No. 4, 246-273.

Myers, S. S. (2017). Planetary health: protecting human health on a rapidly changing planet. Lancet, 390, 2860-2868. 
Ng, H. B., Qi, C. W. \& Tan, X. M. (2009). Covered anaerobic lagoons with HDPE geomembrane experiences in developing Asian countries. Proceedings of the International Symposium on Environmental Engineering, Hangzhou, China, Chen, Y., Tang, X. and Zhan, L., Editors. Springer, Berlin, Germany, pp. 828-833.

Norberg, J. (2016). Progress: 10 Reasons to look Forward to the Future, Oneworld publications, London, UK. Read in French: Non ce n'était pas mieux avant: 10 bonnes raisons d'avoir confiance en l'avenir, Plon, Paris, France.

Noval, A., Blanco, M., Farcas, F., Aguiar, E., Castillo, F. \& Touze-Foltz, N. (2014). Long-term performance of EPDM geomembrane in El Boqueron reservoir. Geosynthetics International, 21, No. 6, 387-398.

OJEC (Official Journal of the European Communities) (1999). Council Directive 1999/31/EC of 26 April 1999 on the landfill of waste. Official Journal of the European Communities, L 182, 16.07.1999, L182/1-L182-19.

Palma, D., Santos-Ferreira, A. \& de Silva, P. (2016). Ofir spit (Portugal): an assessment of geotubes performance in coastal protection. Proceedings Geotechnics for Sustainable Infrastructure Development - Geotech Hanoi 2016, Hanoi, Vietnam, pp. $983-990$.

Palmeira, E. (2012). Embankments. Chapter 5, Handbook of Geosynthetic Engineering, 2nd edition, Shukla, S. K., Editor, ICE Publishing, London, UK, pp. 101-127.

Parker, G. (2013). Global Crisis: War, Climate Change \& Catastrophe in the Seventeenth Century, Yale University Press, New Haven and London, UK. ISBN 978-0 300-20863-4.

Peggs, I. D. (2008). Observations and thoughts on the performance of polypropylene geomembrane liners and floating covers: towards improved specifications. Proceedings Eurogeo 4, Edinburgh, UK, Dixon, N., Editor, $7 \mathrm{p}$

Perkins, S. W., Berg, R. R. \& Christopher, B. R. (2012). Paved roads. In Handbook of Geosynthetic Engineering, Second Edition (Shukla, S. K., Editor). ICE, London, UK, pp. 179-192.

Piorunski, R. (1998). Le détour d'un grec par la Chine. Entretien avec François Jullien. Ebisu - Etudes Japonaises, 18, 147-185 (in French).

Pons, C., Farcas, F., Mkademi, H., Richaud, E. \& Fayolle, B. (2012). Behavior of antioxidants in HDPE geomembranes used in municipal solid waste landfills. Proceedings Eurogeo 2012, Valencia, Spain, Blanco, M., Leiro, A., Mateo, B., Torregrosa, J. B., Abad, F., Pardo de Santayama, F. and Santalla, J., Editors, vol. 5, pp. 237-244.

Porter, S. D. \& Reay, D. S. (2015). Addressing food supply chain and consumption inefficiencies: potential for climate change mitigation. Regional Environmental Change, 16, No. 8, 2279-2290.

Poulain, D., Touze-Foltz, N., Peyras, L. \& Duquennoi, C. (2012). Containment ponds, reservoirs and canals. In Handbook of Geosynthetic Engineering (Shukla, S. K., Editor). ICE, London, UK, pp. 279-302.

Raja, J., Dixon, N., Fowmes, G., Frost, M. \& Assinder, P. (2015). Obtaining reliable embodied carbon values for geosynthetics. Geosynthetics International, 22, No. 5, 393-401.

Redón-Santafé, M., Ferrer Gisbert, P. S., Sánchez Romero, F. J., Torregrosa Soler, J. B., Ferrán Gozálvez, J. J. \& Ferrer Gisbert, C. M. (2014). Implementation of a photovoltaic floating cover for irrigation reservoirs. Journal of Cleaner Production, 66, 568-570.

Ritzema, H. P. (2016). Drain for gain: managing salinity in irrigated lands - a review. Agricultural Water Management, 176, 18-28.

Rowe, R. K. (1998). Geosynthetics and the minimization of contaminant migration through barrier systems beneath solid waste. Keynote Lecture, Proceedings of 6th International Conference on Geosynthetics, Atlanta, GA, USA, Rowe, R. K., Editor, IFAI, Roseville, MN, USA, vol. 1, pp. 27-103.

Rowe, R. K. \& Brachman, R. W.I. (2004). Assessment of equivalence of composite liners. Geosynthetics International, 11, No. 4, 273-286.

Rowe, R. K., Quigley, R. M., Brachman, R. W. I. \& Booker, J. R. (2004). Barrier Systems for Waste Disposal Facilities, 2nd Edition, Spon Press, Oxford, UK.
Russell, A. R., Chapman, M., Teh, S. H. \& Wiedmann, T. (2017). Cost and embodied carbon reductions in cutter soil mix walls through fibre reinforcement, Geosynthetics International, 24, No. 3, 280-292.

Sadlier, M. \& Taylor, R. (2002). Recent developments in polyethylene geomembranes for use in floating covers. Proceedings 7 th International Conference on Geosynthetics, Nice, France, Delmas, Ph. and Gourc, J. P., Editors. Balkema, Rottermadam, The Netherlands, vol. 2, pp. 719-722.

Saengrungruang, P. \& Boyd, C. E. (2014). Evaluation of porous, geotextile liners for erosion control in small aquaculture ponds. North American Journal of Aquaculture, 76, No. 4, 369-374.

Shimaoka, T., Kumahgai, K., Katsumi, T. \& Iba, M. (2014). Design, installation, and maintenance of temporary storage sites for radioactive decontamination waste. Proceedings 15th Asian Regional Conference on Soil Mechanics and Geotechnical Engineering, Fukuoka, Japan, pp. 2385-2390.

Shukla, S. K. (1997). A study on causes of landslides in Arunachal Pradesh. Proceedings of the Indian Geotechnical Conference, Vadorara, India, pp. 613-616.

Shukla, S. K., Sivakugan, N. \& Das, B. M. (2012). Slopes-stabilization. In Handbook of Geosynthetic Engineering, second edition, Shukla, S. K., Editor, ICE, London, UK, pp. 223-243.

Simon, J. (1995). The State of Humanity: Steadily Improving. Wiley, Hoboken, NJ, USA, Cato policy report.

Snars, K. \& Gilkes, R. J. (2009). Evaluation of bauxite residues (red muds) of different origins for environmental applications. Applied Clay Science, 46, 13-20.

Sprague, C. J. \& Sprague, J. E. (2016). Chapter 24: geosynthetics in erosion and sediment control. Geotextiles, From Design to Applications, Koerner, R. M., Editor. Elsevier, Amsterdam, The Netherlands, pp. 531-562.

Tatsuoka, F. (2006). A message from the new IGS president for 2006 to 2010. IGS News, 22, No. 3, 1-2.

Tatsuoka, F., Tateyama, M., Uchimura, T. \& Koseki, J. (1997). Geosynthetic reinforced soil retaining walls as important permanent structures. 1996-1997 Mercer Lecture. Geosynthetics International, 4, No. 2, 81-136.

Tatsuoka, F., Tateyama, M., Koda, M., Kojima, K. I., Yonezawa, T., Shindo, Y. \& Tamai, S. I. (2014). Research and construction of geosynthetic-reinforced soil integral bridges. Transportation Geotechnics, 8, 4-25.

The Lancet Commissions (2017). The Lancet Commission on pollution and health. Lancet, 391, No. 10119, 462-512.

Thuan, T. X. (2013). The cosmos and the lotus, the pocket book. French Version, Le cosmos et le lotus, Albin Michel, Paris, France.

Touze-Foltz, N. (2014). Etat de l'art sur les contraintes et caractéristiques des solutions techniques par géosynthétiques pour stocker les effluents d'élevage ou eaux chargés (effluents bovins ou volailles), Internal report Irstea. Convention MAAF (DGPPAT/S DIR B\&E/BSE) - Irstea. Agriculture et gestion durable de l'eau 2012-2014 (in French).

Touze-Foltz, N., Barroso, M. \& Cartaud, F. (2006). Experimental investigation of flow rates through composite liners at the metric scale. Proceedings 8th International Conference on Geosynthetics, Yokohama, Japan, Kuwano, J. and Koseki, J., Editors. Millpress, Rotterdam, The Netherlands, pp. 305-308.

Touze-Foltz, N., Lupo, J. \& Barroso, M. (2008). Geoenvironmental applications of geosynthetics. Keynote Lecture, Proceedings Eurogeo 4, Edinburgh, UK, Dixon, N., Editor, 98p.

Touze-Foltz, N., Croissant, D., Farcas, F. \& Royet, P. (2010). Quantification of oxidized bituminous geomembranes ageing through hydraulic testing. Proceedings 9th International Conference on Geosynthetics, Guaruja, Brazil. Brazilian Chapter of the International Geosynthetics Society (IGSBrazil), São Paulo, Brazil, pp. 753-756.

Touze-Foltz, N., Bannour, H., Barral, C. \& Stoltz, G. (2016). A review of the performance of geosynthetics for environmental protection. Geotextiles and Geomembranes, 44, No. 5, 656-672. 
UN (United Nations) (2015). Transforming our World: the 2030 Agenda for Sustainable Development, Document A/RES/70/1. UN, New York, NY, USA.

Vanleberghe, C. (2017). La montée des eaux va aggraver les inondations. Le Figaro, No. 22721, p. 6 (in French).

Venkatappa Rao, G. (2016). Indian perspectives - achievements and projections. Proceedings 6th Asian Regional Conference on Geosynthetics - Geosynthetics for Infrastructure Development, New Delhi, India, pp. HL3-HL36.

Werth, K., Höhny, S., Stucki, M., Büsser, S., Itten, R., Frischknecht, R. \& Wallbaum, H. (2012). Comparative life cycle assessment of geosynthetics versus conventional construction materials, a study on behalf of the E.A.G.M., Case 3, landfill construction drainage layer. Proceedings 5th European Geosynthetics Congress, Valencia, Spain, Blanco, M., Leiro, A., Mateo, B., Torregrosa, J. B., Abad, F., Pardo de Santayama, F. and Santalla, J., Editors, vol. 5, pp. 300-303.

WRAP (Waste and Resources Action Programme) (2010). Sustainable Geosystems in Civil Engineering Applications, Project MRF116. Waste and Resources Action Programme, Banbury, UK.
Yonezawa, T., Yamazaki, T., Tateyama, M. \& Tatsuoka, F. (2014). Design and construction of geosynthetic-reinforced soil structures for Hokkaido high-speed train line. Transportation Geotechnics, 1, No. 1, 3-20.

Yoo, C. (2015). Global warming: implications to geosynthetic reinforced soil walls design. The 2nd International GSI-Asia Geosynthetics Conference (GSI Asia 2015), Seoul, Korea, Jeon, H. Y., Editor, The Geosynthetics Institute, Seoul, Korea, 6p.

Zornberg, G. (2012). President's corner: the council of the IGS. IGS News, 28, No. 2, 2.

Zornberg, G. (2013). No borders for the good use of geosynthetics. GRI-25. The Geosynthetic Institute, Philadelphia, PA, USA, pp. $342-357$.

Zornberg, J. G. (2017a). Functions and applications of geosynthetics in roadways - Part 1. Geosynthetics Magazine, February March, $34-41$.

Zornberg, J. G. (2017b). Functions and applications of geosynthetics in roadways - Part 2. Geosynthetics Magazine, April May, $34-41$.

The Editor welcomes discussion on all papers published in Geosynthetics International. Please email your contribution to discussion@geosynthetics-international.com by 15 August 2021. 